\title{
Hepatic resection alone versus in combination with pre- and post-operative transarterial chemoembolization for the treatment of hepatocellular carcinoma: A systematic review and meta-analysis
}

\author{
Xingshun $\mathrm{Qi}^{1,{ }^{1}{ }^{*} \text {, Lei Liu }}{ }^{2, *}$, Diya Wang ${ }^{3, *}$, Hongyu $\mathrm{Li}^{1}$, Chunping Su${ }^{4}$, Xiaozhong Guo ${ }^{1}$ \\ ${ }^{1}$ Department of Gastroenterology, General Hospital of Shenyang Military Area, Shenyang, China \\ ${ }^{2}$ Xijing Hospital of Digestive Diseases, Fourth Military Medical University, Xi'an, China \\ ${ }^{3}$ Department of Occupational and Environmental Health Sciences and the Ministry of Education Key Lab of Hazard Assessment \\ and Control in Special Operational Environment, School of Public Health, Fourth Military Medical University, Xi'an, China \\ ${ }^{4}$ Library of Fourth Military Medical University, Xi'an, China \\ *These authors have contributed equally to this work \\ Correspondence to: \\ Xiaozhong Guo, e-mail: guo_xiao_zhong@126.com \\ Xingshun Qi, e-mail: xingshunqi@126.com \\ Keywords: Clinical Section, hepatocellular carcinoma, hepatic resection, transarterial chemoembolization, survival, recurrence \\ Received: June 13, 2015 \\ Accepted: September 22, 2015 \\ Published: October 05, 2015
}

\section{ABSTRACT}

Background and Aims: The prognosis of hepatocellular carcinoma (HCC) treated with hepatic resection may be improved by the adjunctive use of transarterial chemoembolization (TACE). This study aimed to systematically compare the outcomes between hepatic resection with and without TACE groups.

Methods: All relevant randomized controlled trials (RCTs) and non-RCTs were searched by the PubMed, EMBASE, and Cochrane Library databases. Overall survival (OS) and disease-free survival (DFS) were two major outcomes. Meta-analyses were performed according to the timing of TACE (pre- or post-operative TACE). Subgroup analyses were also performed. Hazard ratios (HRs) with $95 \%$ confidence intervals (95\%CIs) were calculated.

Results: Overall, 55 papers were included (14 RCTs and 41 non-RCTs). Overall meta-analyses demonstrated that OS and DFS were statistically similar between hepatic resection with and without pre-operative TACE groups (HR $=1.01$, $95 \% \mathrm{CI}=0.87-1.19, P=0.87 ; \mathrm{HR}=0.91,95 \% \mathrm{CI}=0.82-1.01, P=0.07)$. Subgroup analyses of RCTs or non-RCTs showed that OS and DFS remained statistically similar between hepatic resection with and without pre-operative TACE groups. Subgroup analysis of incomplete or no tumor necrosis showed that OS was worse in hepatic resection with pre-operative TACE group than in hepatic resection without preoperative TACE group. By contrast, subgroup analysis of complete tumor necrosis showed that DFS was better in hepatic resection with pre-operative TACE group than in hepatic resection without pre-operative TACE group.

Overall meta-analyses demonstrated that OS and DFS were better in hepatic resection with post-operative TACE group than in hepatic resection without postoperative TACE group $(\mathrm{HR}=0.85,95 \% \mathrm{CI}=0.72-1.00, P=0.06 ; \mathrm{HR}=0.83$, $95 \% C I=0.73-0.94, P=0.004)$. Subgroup analyses of RCTs, vascular invasion, or large HCC showed that OS and DFS remained better in hepatic resection with postoperative TACE group than in hepatic resection without post-operative TACE group. By contrast, subgroup analyses of non-RCTs, no vascular invasion, or small HCC showed that OS and DFS were statistically similar between the two groups. 


\section{Conclusions: Post-operative TACE, rather than pre-operative TACE, may be considered as an adjunctive treatment option for HCC treated with hepatic resection.}

\section{INTRODUCTION}

Hepatocellular carcinoma (HCC) is one of the most lethal malignancies in the world [1-2]. Hepatic resection is a curative treatment option for HCC [3-4]. The current practice guidelines recommend that hepatic resection should be employed for the treatment of early HCC with single nodule and normal liver function but without clinically significant portal hypertension [5]. Recent metaanalyses have shown a statistically significant survival benefit of hepatic resection over radiofrequency ablation in small $\mathrm{HCC}$, especially in $\mathrm{HCC}$ with $>3 \mathrm{~cm}$ nodule [6-7]. On the other hand, accumulated evidence also suggests that the indications for hepatic resection may be further extended outside the early stage of HCC [8-10]. In clinical practices, more and more patients are considered as the candidates for hepatic resection due to the improvement of diagnostic methods, early surveillance, and surgical skills [11]. However, the residual tumor and tumor recurrence after resection remained an unresolved issue [12-13].

Transarterial chemoembolization (TACE) is recommended as the standard treatment option for $\mathrm{HCC}$ at intermediate stage [5]. Because the blood supply of HCC is mainly derived from hepatic artery, the use of TACE can lead to the ischemia and necrosis of tumor tissues at the embolization regions. Meta-analyses have also confirmed its significant survival benefit over no treatment [14]. Theoretically, the adjunctive use of TACE before and after hepatic resection may be effective for the prevention of tumor recurrence and improvement of survival in HCC patients. However, due to the inconsistency of conclusions among studies, the use of hepatic resection in combination with adjunctive TACE is not recommended [5].

The aim of our study was to systematically collect the relevant data comparing the outcomes of hepatic resection with and without TACE and to synthesize these data into a more unbiased and balanced result.

\section{RESULTS}

\section{Study selection}

A total of 2037 papers were initially retrieved. Among them, 62 potentially eligible papers were identified. However, one paper was excluded, because the separate data in hepatic resection combined with TACE group could not be obtained [15]; four papers were excluded, because the survival and recurrence data were not provided [16-19]; and two papers were excluded, because they compared the outcomes of prophylactic versus therapeutic TACE for recurrent HCC [20-21]. Finally, 55 papers were included in the systematic review [22-76] (Figure 1).

\section{Study characteristics}

The study characteristics were summarized in Table 1. Among them, 37 papers were cohort studies (retrospective, $n=25$; prospective, $n=2$; unclassified, $n=10$ ), 4 papers were case-control studies (retrospective, $n=1$; propensity score analysis, $n=1$; unclassified, $n=2$ ), and 14 papers were randomized controlled trials (RCTs). They were performed in China $(n=31)$, both China and Japan $(n=1)$, France $(n=2)$, Italy $(n=2)$, Japan $(n=15)$, and Korea $(n=4)$. The patient enrollment was initiated before and after 2000 in 36 and 19 papers, respectively. Pre-operative and post-operative TACE was performed in 32 and 22 papers, respectively. Both pre-operative and post-operative TACE were performed in one paper. As for pre-operative TACE, the interval between TACE and hepatic resection was not available in 11 papers. As for post-operative TACE, the interval between TACE and hepatic resection was not available in 4 papers.

\section{Study quality}

Of the 37 cohort studies, 7 had $0-3$ points, 27 had 4-6 points, and 3 had 7-8 points (Supplementary Table 1). All of the 4 case-control studies had 4-6 points (Supplementary Table 2). Of the 14 RCTs, 1, 8, and 5 had high, unclear, and low risk of bias in random sequence generation, respectively; 2,8 , and 4 had high, unclear, and low risk of bias in allocation concealment, respectively; 3 and 11 had high and unclear risk of bias in blinding of participants and personnel, respectively; 13 and 1 had unclear and low risk of bias in blinding of outcome assessment, respectively; 1,8 , and 5 had high, unclear, and low risk of bias in incomplete outcome data addressed, respectively; and 1 and 13 had high and low risk of bias in selective reporting, respectively (Supplementary Table 3).

\section{Pre-operative TACE}

\section{Overall survival (OS)}

Twenty-four studies reported the OS rate in the two groups. The overall meta-analysis demonstrated a statistically similar OS between hepatic resection with and without pre-operative TACE groups (hazard ratio $[\mathrm{HR}]=1.01,95 \%$ confidence interval $[\mathrm{CI}]=0.87-1.19$, $P=0.87$ ) (Figure 2). The heterogeneity among studies was statistically significant $\left(P<0.00001 ; \mathrm{I}^{2}=81 \%\right)$. The funnel plot suggested a proof of publication bias (Supplementary Figure 1).

In the subgroup analysis of complete tumor necrosis after TACE, the OS remained statistically similar between the two groups $(\mathrm{HR}=1.02,95 \% \mathrm{CI}=0.63-1.66, P=0.93)$ 


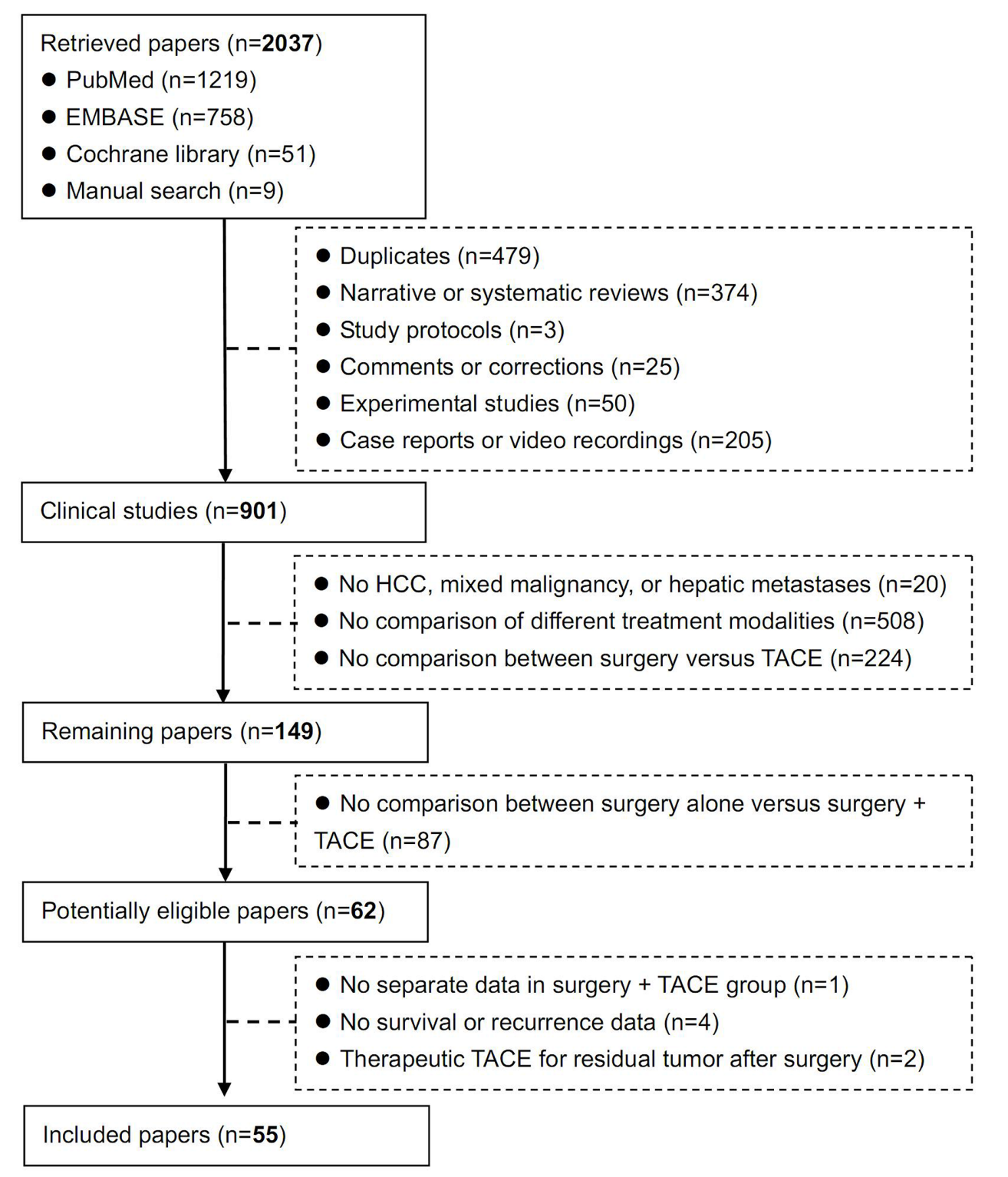

\section{Figure 1: Flowchart of study inclusion.}

(Supplementary Figure 2). However, in the subgroup analysis of incomplete or no tumor necrosis after TACE, the OS was statistically significantly worse in hepatic resection with pre-operative TACE group than in hepatic resection without pre-operative TACE group ( $\mathrm{HR}=2.01$, $95 \% \mathrm{CI}=1.22-3.31, P=0.006)$. The subgroup difference was statistically significant $\left(P=0.06 ; \mathrm{I}^{2}=72.2 \%\right)$.

Regardless of large or small HCC, the OS remained statistically similar between the two groups (in large $\mathrm{HCC}$ : $\mathrm{HR}=0.85,95 \% \mathrm{CI}=0.68-1.07, P=0.18$; in small HCC: $\mathrm{HR}=1.10,95 \% \mathrm{CI}=0.58-2.07, P=0.77$ ) (Supplementary Figure 3 ). There was no statistically significant subgroup difference $\left(P=0.46 ; \mathrm{I}^{2}=0 \%\right)$.

In the subgroup analysis of cirrhotic patients, the OS was statistically significantly better in hepatic resection with pre-operative TACE group than in hepatic resection without pre-operative TACE group ( $\mathrm{HR}=0.67$, $95 \% \mathrm{CI}=0.47-0.96, P=0.03$ ) (Supplementary Figure 4). By comparison, in the subgroup analysis of non-cirrhotic patients, the OS was statistically similar between the two groups ( $\mathrm{HR}=0.63,95 \% \mathrm{CI}=0.17-2.32, P=0.48)$. There was no statistically significant subgroup difference $\left(P=0.92 ; I^{2}=0 \%\right)$.

Regardless of randomized or non-randomized studies, the OS remained statistically similar between the two groups (in RCT: $\mathrm{HR}=0.90$, $95 \% \mathrm{CI}=0.73-1.10, P=0.30$; in non-RCT: $\mathrm{HR}=1.03$, $95 \% \mathrm{CI}=0.86-1.23, P=0.77$ ) (Supplementary Figure 5). There was no statistically significant subgroup difference $\left(P=0.33 ; \mathrm{I}^{2}=0 \%\right)$. 


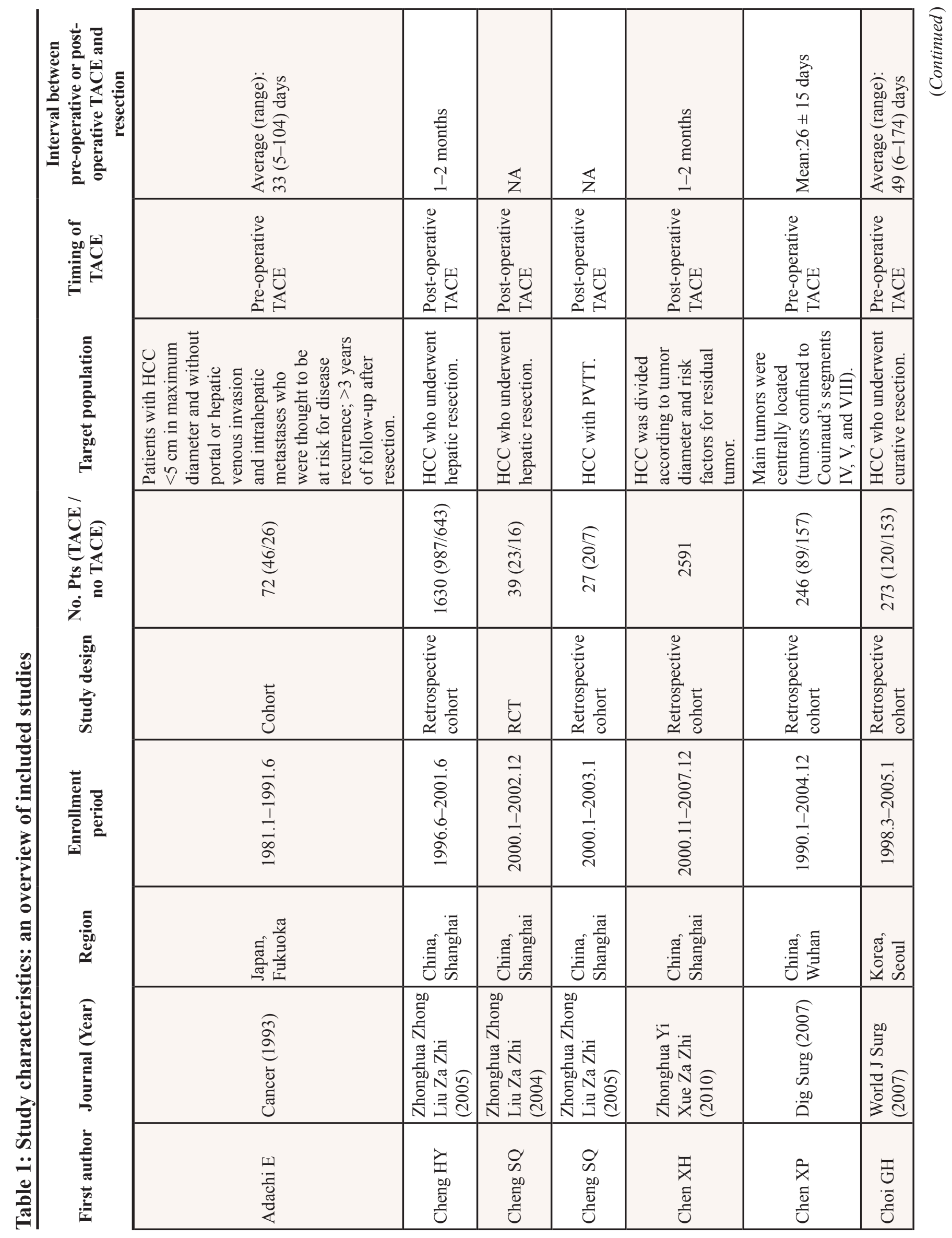




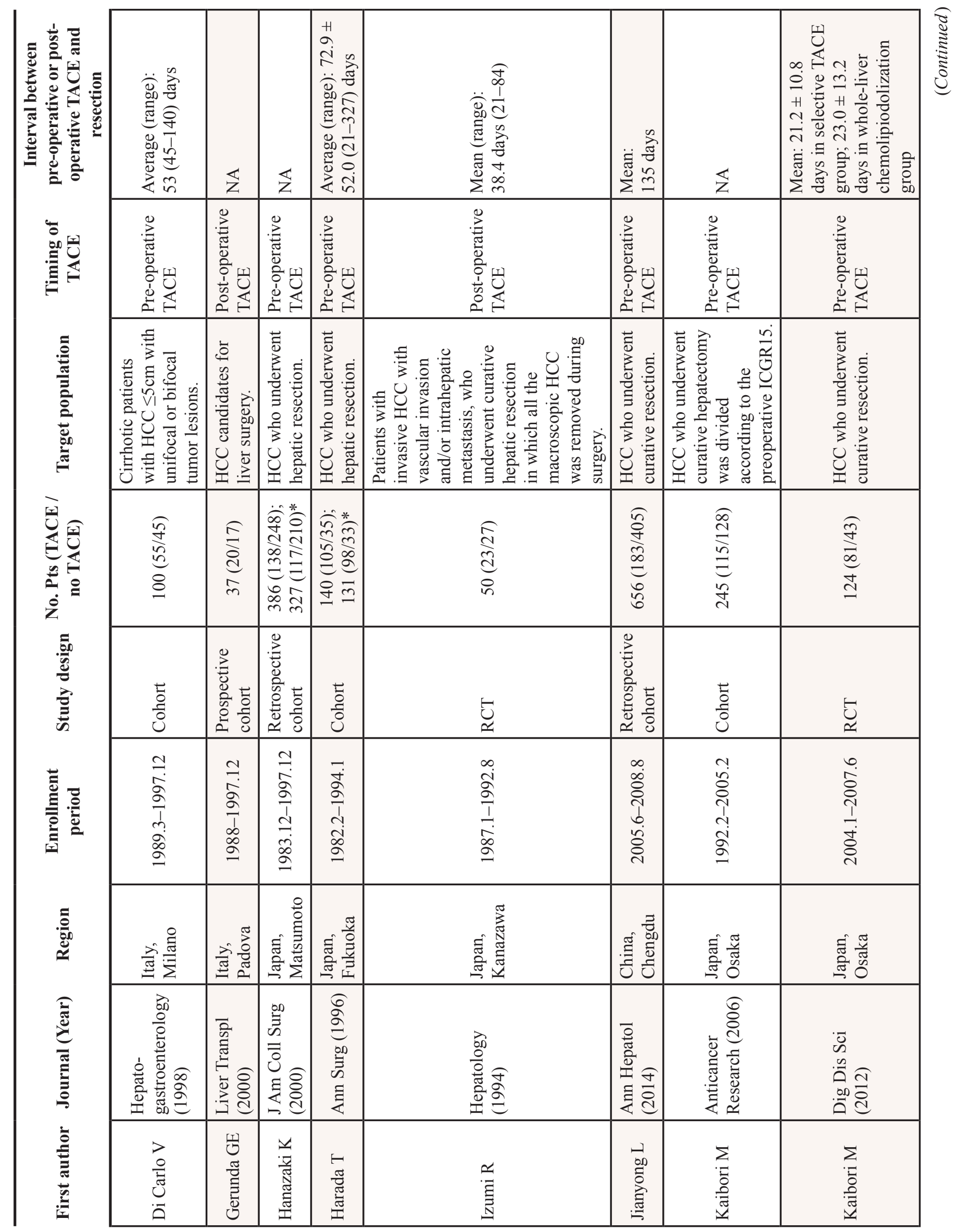




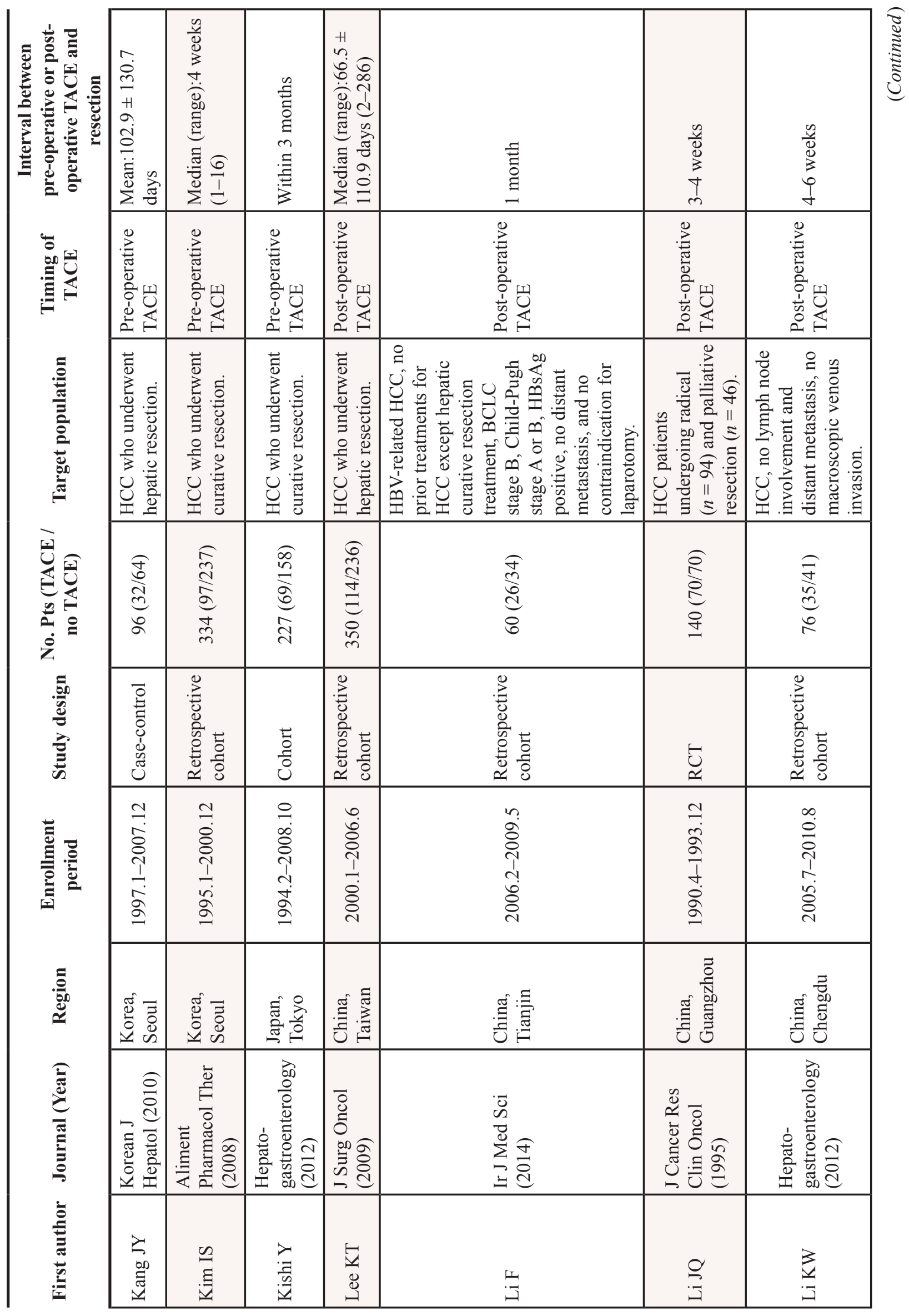




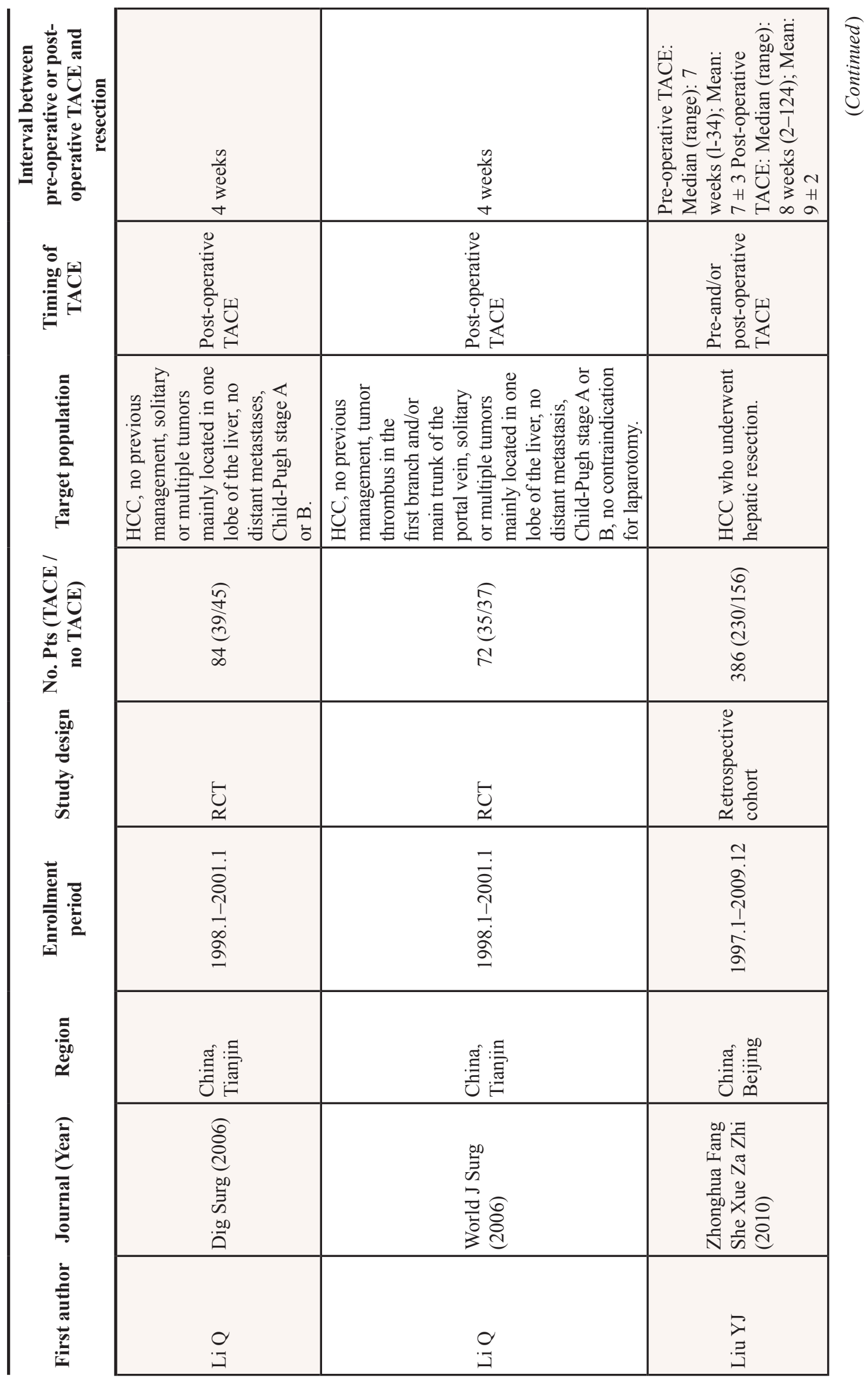




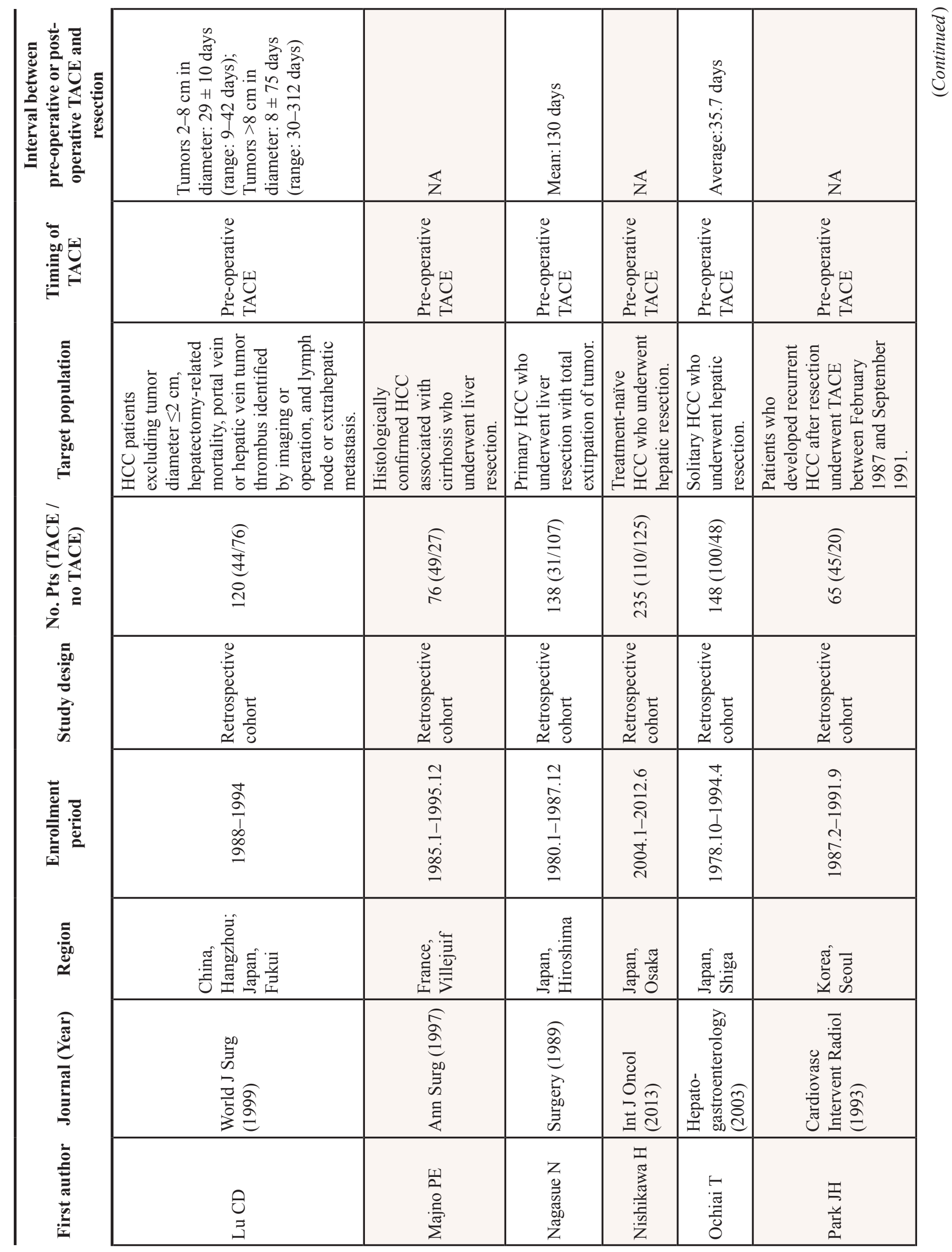




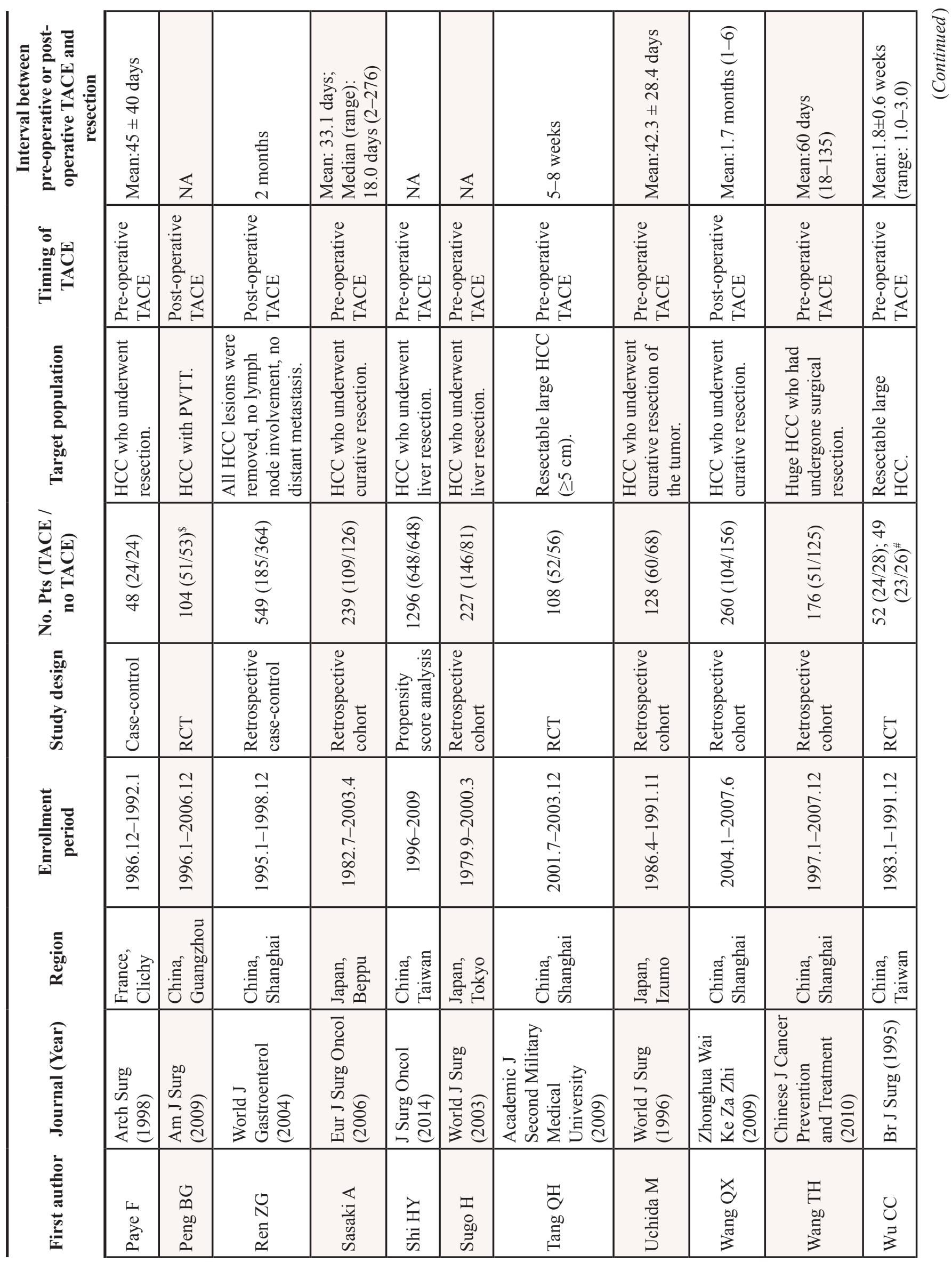




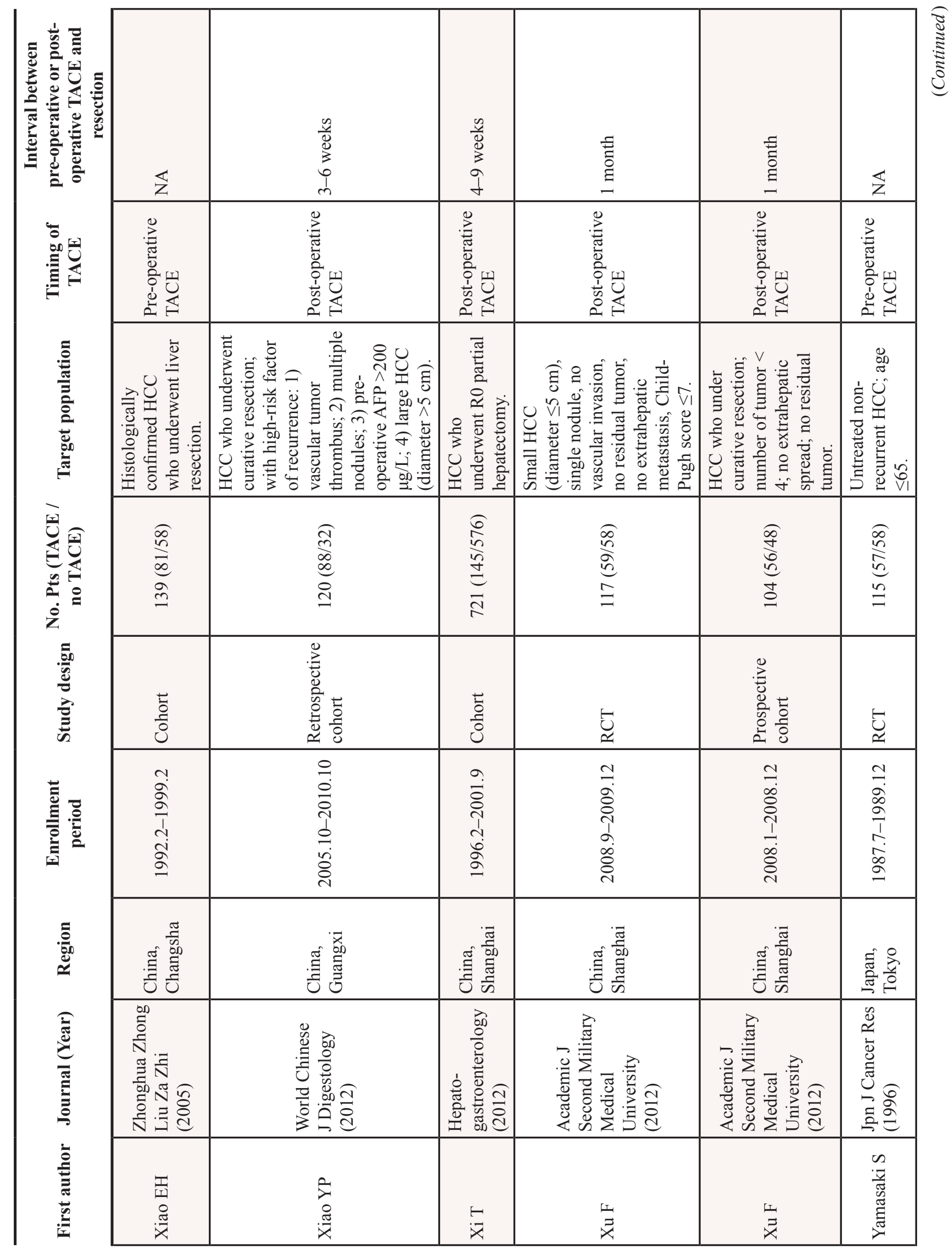




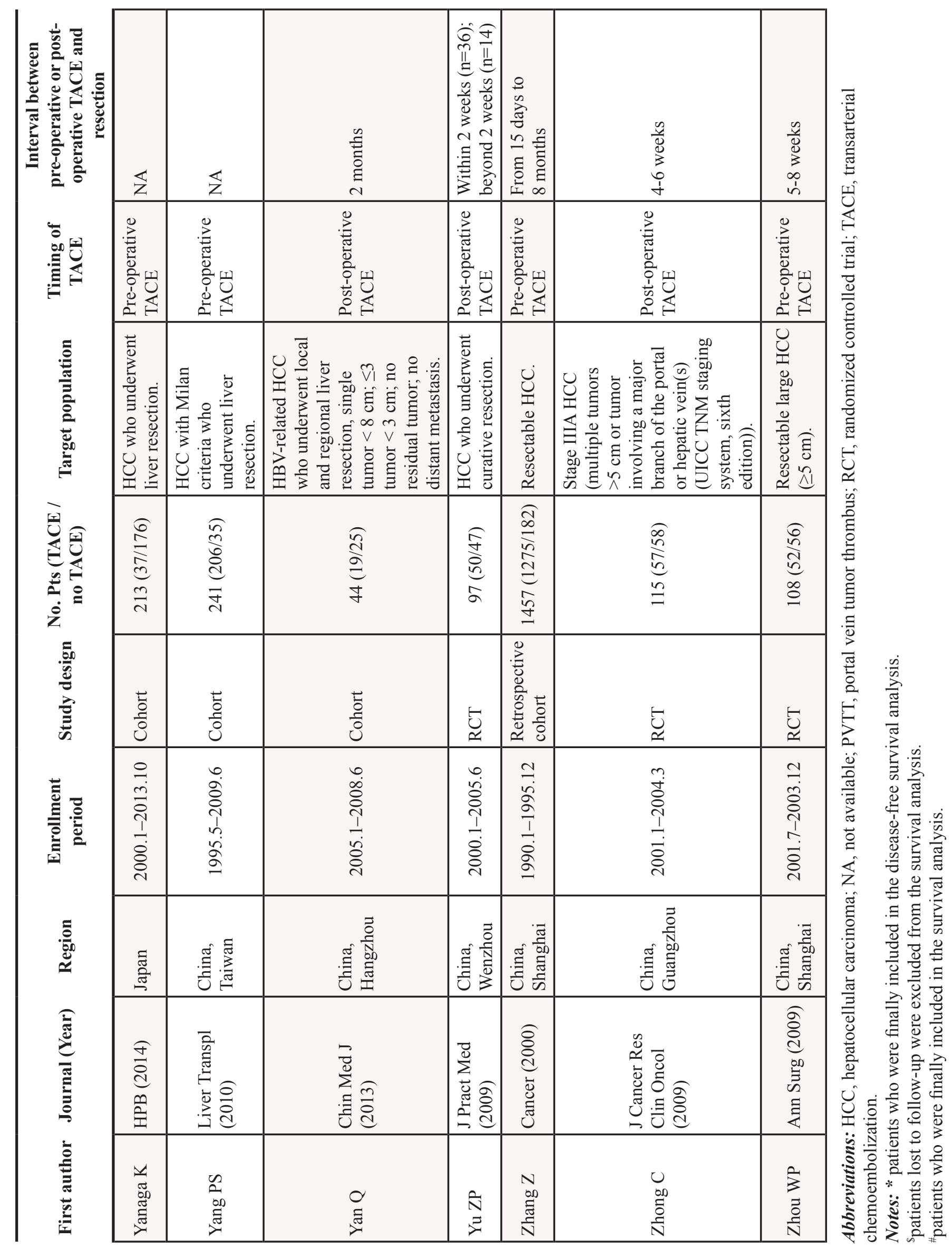




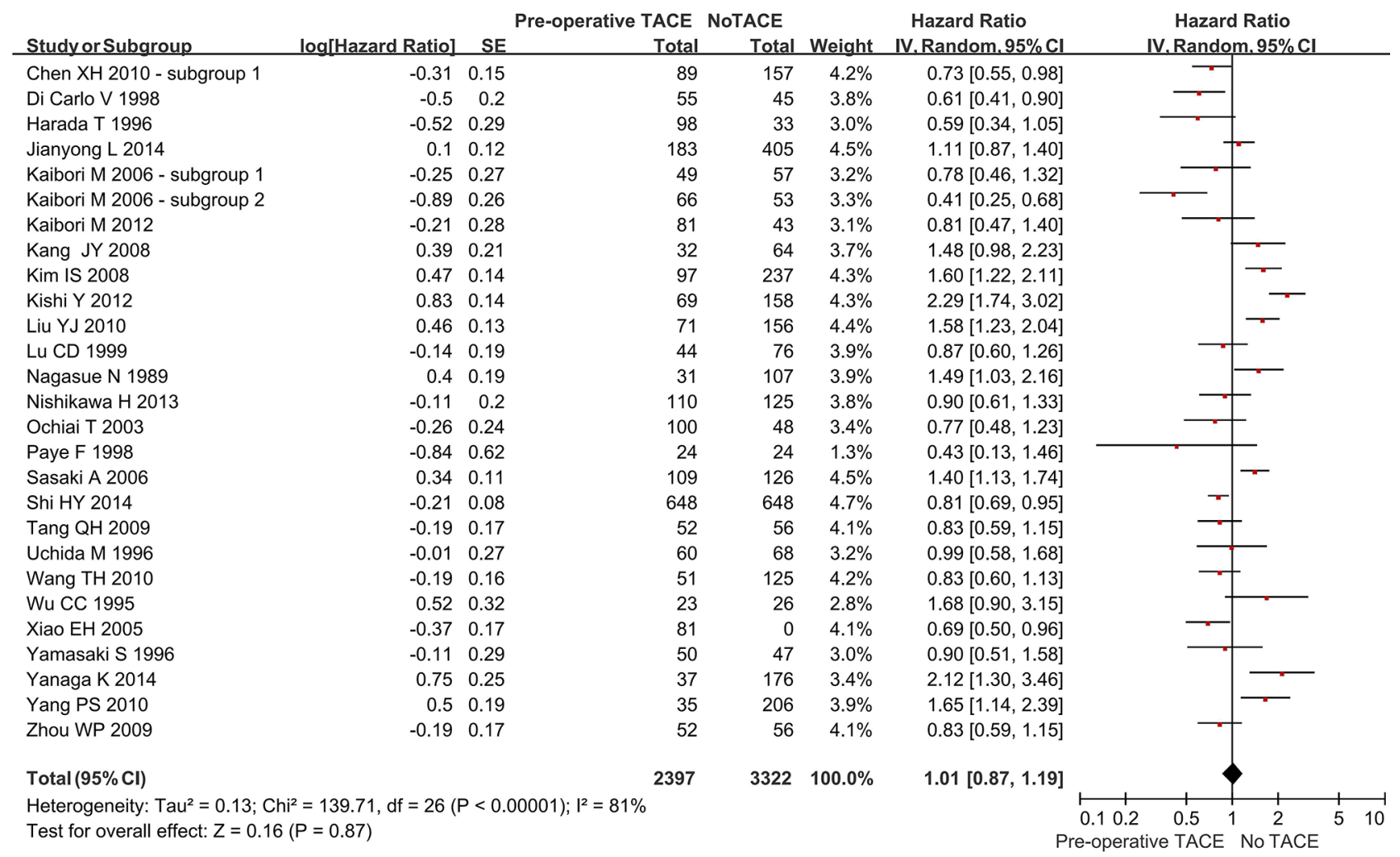

Figure 2: Forest plots comparing the overall survival between hepatic resection with and without pre-operative TACE groups.

\section{Disease-free survival (DFS)}

Twenty-four studies reported the DFS rate in the two groups. The overall meta-analysis demonstrated a better DFS in hepatic resection with pre-operative TACE group than in hepatic resection without pre-operative TACE group. But the difference was not statistically significant $(\mathrm{HR}=0.91,95 \% \mathrm{CI}=0.82-1.01, P=0.07)$ (Figure 3$)$. The heterogeneity among studies was statistically significant $\left(P<0.00001 ; \mathrm{I}^{2}=71 \%\right)$. The funnel plot suggested a proof of publication bias (Supplementary Figure 6).

In the subgroup analysis of complete tumor necrosis after TACE, the DFS was statistically significantly better in hepatic resection with pre-operative TACE group than in hepatic resection without pre-operative TACE group $(\mathrm{HR}=0.67,95 \% \mathrm{CI}=0.58-0.77, P<0.00001)$ (Supplementary Figure 7). However, in the subgroup analysis of incomplete or no tumor necrosis after TACE, the DFS was statistically similar between the two groups (HR $=1.13,95 \% \mathrm{CI}=0.94-1.35, P=0.20)$. The subgroup difference was statistically significant $(P<0.00001$; $\left.\mathrm{I}^{2}=95.1 \%\right)$.

Regardless of large or small HCC, the DFS was statistically similar between the two groups (in large HCC: $\mathrm{HR}=0.86,95 \% \mathrm{CI}=0.69-1.06, P=0.15$; in small HCC: $\mathrm{HR}=1.10,95 \% \mathrm{CI}=0.80-1.50, P=0.56$ ) (Supplementary Figure 8). There was no statistically significant subgroup difference $\left(P=0.20 ; \mathrm{I}^{2}=39.8 \%\right)$.
In the subgroup analysis of cirrhotic patients, the DFS was statistically significantly better in hepatic resection with pre-operative TACE group than in hepatic resection without pre-operative TACE group $(\mathrm{HR}=0.77,95 \% \mathrm{CI}=0.62-0.95, P=0.01)$ (Supplementary Figure 9). No study was identified in the subgroup analysis of non-cirrhotic patients.

Regardless of randomized or non-randomized studies, the DFS was statistically similar between the two groups (in RCT: $\mathrm{HR}=0.92,95 \% \mathrm{CI}=0.79-1.07, P=0.26$; in non-RCT: $\mathrm{HR}=0.90,95 \% \mathrm{CI}=0.81-1.02, P=0.09$ ) (Supplementary Figure 10). There was no statistically significant subgroup difference $\left(P=0.88 ; \mathrm{I}^{2}=0 \%\right)$.

\section{Free of recurrence}

Two studies reported the recurrence rate in the two groups. Both of them demonstrated a higher overall rate free of recurrence in hepatic resection without preoperative TACE group than in hepatic resection with pre-operative TACE group (39.7\% versus $27.5 \%$; $62 \%$ versus $51 \%)$.

\section{Post-operative TACE}

OS

Sixteen studies reported the OS rate in the two groups. The overall meta-analysis demonstrated a better OS in hepatic resection with post-operative TACE group 


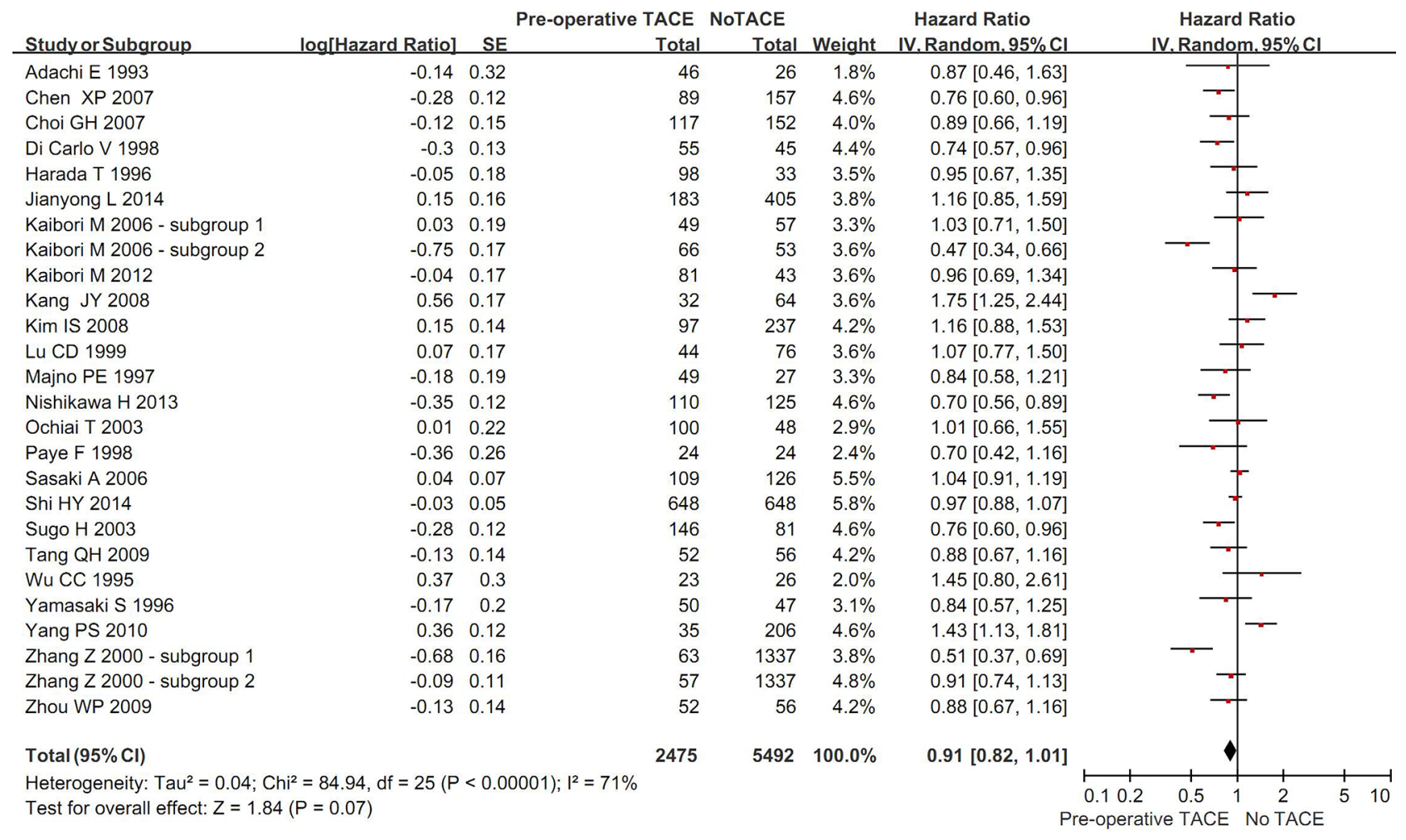

Figure 3: Forest plots comparing the disease-free survival between hepatic resection with and without pre-operative TACE groups.

than in hepatic resection without post-operative TACE group. But the difference was not statistically significant $(\mathrm{HR}=0.85,95 \% \mathrm{CI}=0.72-1.00, P=0.06)$ (Figure 4). The heterogeneity among studies was statistically significant $\left(P<0.00001 ; \mathrm{I}^{2}=70 \%\right)$. The funnel plot suggested a proof of publication bias (Supplementary Figure 11).

In the subgroup analysis of vascular invasion, the OS was statistically significantly better in hepatic resection with post-operative TACE group than in hepatic resection without post-operative TACE group ( $\mathrm{HR}=0.80,95 \%$ $\mathrm{CI}=0.69-0.92, P=0.002$ ) (Supplementary Figure 12). However, in the subgroup analysis of no vascular invasion, the OS was statistically similar between the two groups $(\mathrm{HR}=0.90,95 \% \mathrm{CI}=0.59-1.38, P=0.64)$. The subgroup difference was not statistically significant $(P=0.57$; $\left.\mathrm{I}^{2}=0 \%\right)$.

In the subgroup analysis of large HCC, the OS was statistically significantly better in hepatic resection with post-operative TACE group than in hepatic resection without post-operative TACE group (HR $=0.77,95 \%$ $\mathrm{CI}=0.65-0.90, P=0.001)$ (Supplementary Figure 13). In the subgroup analysis of small HCC, the OS was better in hepatic resection with post-operative TACE group than in hepatic resection without post-operative TACE group. But the difference was not statistically significant $(\mathrm{HR}=1.39,95 \% \mathrm{CI}=0.98-1.98, P=0.07)$. The subgroup difference was statistically significant $\left(P=0.003 ; \mathrm{I}^{2}=89.0 \%\right)$.
In the subgroup analysis of randomized studies, the OS was statistically significantly better in hepatic resection with post-operative TACE group than in hepatic resection without post-operative TACE group (HR $=0.67,95 \%$ $\mathrm{CI}=0.57-0.79, P<0.00001)$ (Supplementary Figure 14). However, in the subgroup analysis of non-randomized studies, the OS was statistically similar between the two groups (HR $=0.98,95 \% \mathrm{CI}=0.81-1.19, P=0.82$ ). The subgroup difference was statistically significant $\left(P=0.003 ; \mathrm{I}^{2}=88.7 \%\right)$.

\section{DFS}

Ten studies reported the DFS rate in the two groups. The overall meta-analysis demonstrated a statistically significantly better DFS in hepatic resection with post-operative TACE group than in hepatic resection without post-operative TACE group (HR $=0.83,95 \%$ $\mathrm{CI}=0.73-0.94, P=0.004$ ) (Figure 5). The heterogeneity among studies was statistically significant $(P=0.06$; $\left.\mathrm{I}^{2}=46 \%\right)$. The funnel plot suggested a proof of publication bias (Supplementary Figure 15).

In the subgroup analysis of vascular invasion, the DFS was statistically significantly better in hepatic resection with post-operative TACE group than in hepatic resection without post-operative TACE group ( $\mathrm{HR}=0.82$, $95 \%$ CI $=0.71-0.94, \quad P=0.004$ ) (Supplementary Figure 16). However, in the subgroup analysis of no vascular invasion, the DFS was statistically similar 


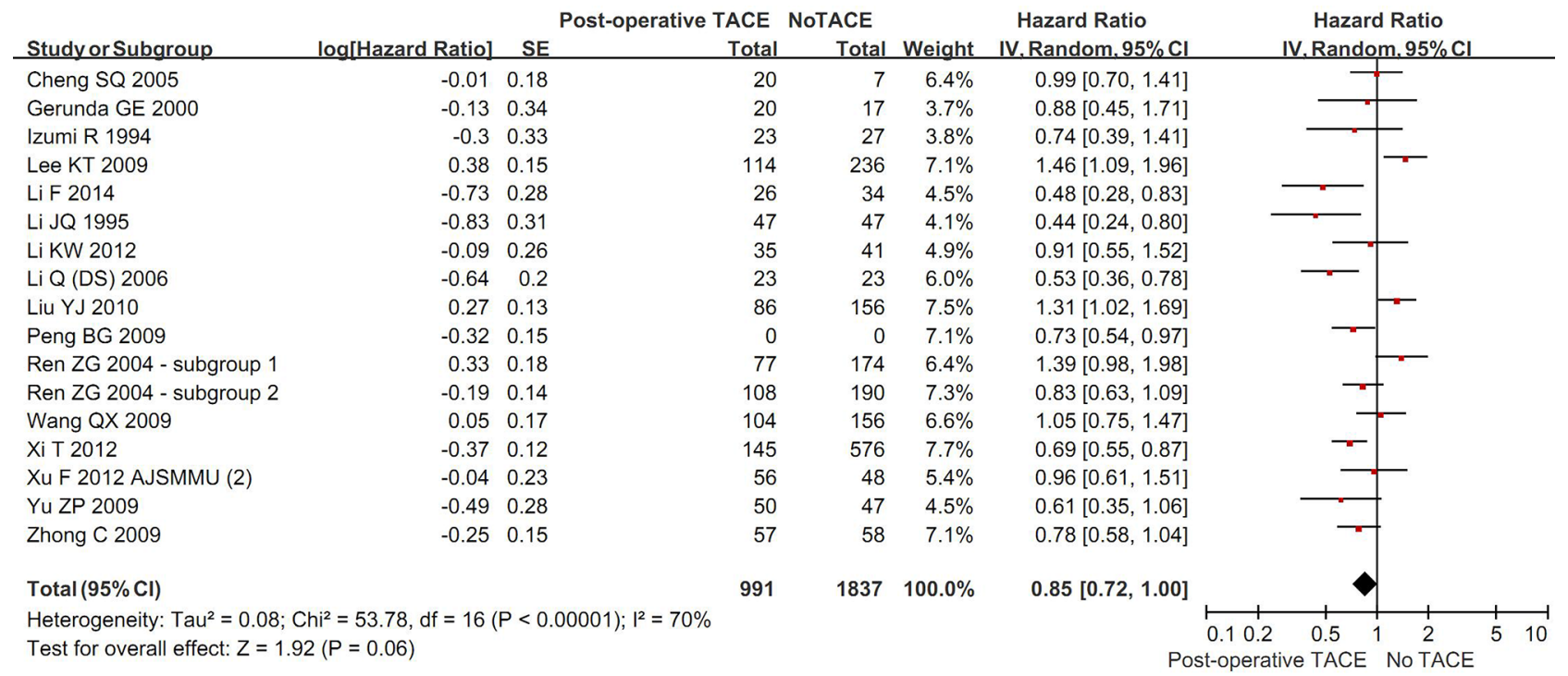

Figure 4: Forest plots comparing the overall survival between hepatic resection with and without post-operative TACE groups.

between the two groups $(\mathrm{HR}=0.97,95 \% \mathrm{CI}=0.60-1.56$, $P=0.90)$. The subgroup difference was not statistically significant $\left(P=0.50 ; \mathrm{I}^{2}=0 \%\right)$.

In the subgroup analysis of large $\mathrm{HCC}$, the DFS was statistically significantly better in hepatic resection with post-operative TACE group than in hepatic resection without post-operative TACE group $(\mathrm{HR}=0.80,95 \% \mathrm{CI}=0.69-0.92, P=0.003)$ (Supplementary Figure 17). In the subgroup analysis of small HCC, the DFS was better in hepatic resection with post-operative TACE group than in hepatic resection without post-operative TACE group. But the difference was not statistically significant $(\mathrm{HR}=0.85,95 \%$ $\mathrm{CI}=0.72-1.01, P=0.07)$. The subgroup difference was not statistically significant $\left(P=0.54 ; \mathrm{I}^{2}=0 \%\right)$.

In the subgroup analysis of randomized studies, the DFS was statistically significantly better in hepatic resection with post-operative TACE group than in hepatic resection without post-operative TACE group $(\mathrm{HR}=0.81$, $95 \% \mathrm{CI}=0.71-0.92, \quad P=0.001$ ) (Supplementary Figure 18). However, in the subgroup analysis of nonrandomized studies, the DFS was statistically similar between the two groups $(\mathrm{HR}=0.86,95 \% \mathrm{CI}=0.68-1.09$, $P=0.21)$. The subgroup difference was statistically significant $\left(P=0.66 ; \mathrm{I}^{2}=0 \%\right)$.

\section{Free of recurrence}

Eight studies reported the recurrence rate in the two groups. The overall meta-analysis demonstrated a statistically similar rate free of recurrence between hepatic resection with and without post-operative TACE groups $(\mathrm{HR}=0.96,95 \% \mathrm{CI}=0.83-1.11, P=0.56)$ (Figure 6). The heterogeneity among studies was statistically significant $\left(P=0.004 ; \mathrm{I}^{2}=60 \%\right)$. The funnel plot suggested a proof of publication bias (Supplementary Figure 19).

In the subgroup analysis of vascular invasion, the rate free of recurrence was statistically significantly higher in hepatic resection with post-operative TACE group than in hepatic resection without post-operative TACE group $(\mathrm{HR}=0.58,95 \% \mathrm{CI}=0.38-0.87, P=0.008)$ (Supplementary Figure 20). However, in the subgroup analysis of no vascular invasion, the rate free of recurrence was statistically similar between the two groups $(\mathrm{HR}=0.92,95 \% \mathrm{CI}=0.53-1.61, P=0.77)$. The subgroup difference was not statistically significant $(P=0.19$; $\left.\mathrm{I}^{2}=42.7 \%\right)$.

Regardless of large or small $\mathrm{HCC}$, the rate free of recurrence was statistically similar between the two groups (in large HCC: $\mathrm{HR}=0.82,95 \% \mathrm{CI}=0.53-1.28, P=0.39$; in small HCC: $\mathrm{HR}=0.97,95 \% \mathrm{CI}=0.68-1.38, P=0.86$ ) (Supplementary Figure 21). There was no statistically significant subgroup difference $\left(P=0.58 ; \mathrm{I}^{2}=0 \%\right)$.

Regardless of randomized or non-randomized studies, the rate free of recurrence was statistically similar between the two groups (in RCT: HR $=0.84,95 \%$ $\mathrm{CI}=0.58-1.21, P=0.34$; in non-RCT: $\mathrm{HR}=0.98,95 \%$ $\mathrm{CI}=0.82-1.17, P=0.83$ ) (Supplementary Figure 22). There was no statistically significant subgroup difference $\left(P=0.44 ; \mathrm{I}^{2}=0 \%\right)$.

\section{DISCUSSION}

We identified a relatively large number of relevant papers evaluating the role of adjunctive TACE for the management of HCC patients treated with hepatic resection. The main findings of our systematic review and meta-analysis were as follows: 1) pre-operative TACE did 


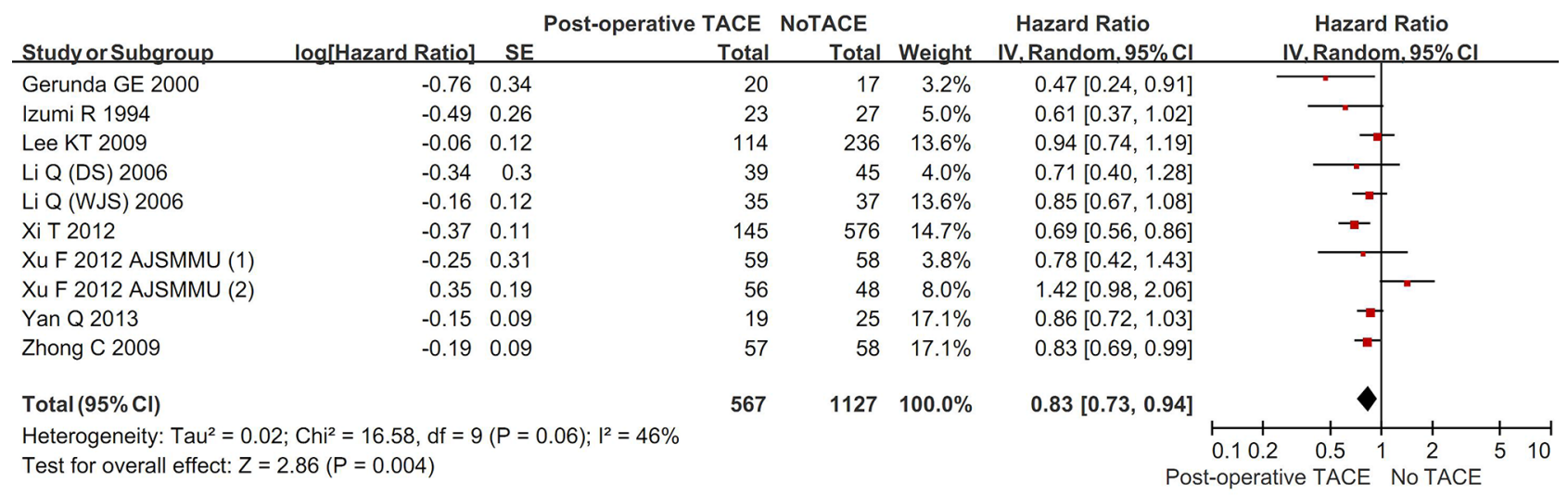

Figure 5: Forest plots comparing the disease-free survival between hepatic resection with and without post-operative TACE groups.

not significantly improve the OS and DFS of HCC patients treated with hepatic resection; and 2) post-operative TACE significantly improved the DFS of HCC patients treated with hepatic resection, but not the OS or recurrence. Before our findings were discussed, several previous metaanalyses should be acknowledged.

As for the pre-operative TACE, 3 meta-analyses were reported. In 2011, Wang et al. published a metaanalysis of 3 RCTs involving 257 patients to identify the effect of pre-operative TACE for resectable HCC [77]. They suggested no significant benefits of pre-operative TACE for the 5-year DFS and OS. In 2013, Yu et al. performed a meta-analysis of 7 retrospective studies to evaluate the effect of pre-operative TACE on resectable HCC [78]. There was a trend toward a better 3-year DFS in pre-operative TACE group, but the difference was not statistically significant. By comparison, the 5-year DFS rate was significantly higher in pre-operative TACE group than in non-TACE group. In addition, the 5-year OS rate was significantly improved by pre-operative TACE. At the same year, Zhou et al. also conducted a larger meta-analysis of 21 studies (4 RCTs and 17 vnonRCTs) involving $3210 \mathrm{HCC}$ patients to explore the benefits of pre-operative TACE for resectable HCC [79]. They demonstrated that pre-operative TACE did not significantly improve the DFS or OS of resectable HCC.

As for the post-operative TACE, 1 meta-analysis was reported. In 2010, Zhong et al. performed a metaanalysis of 6 RCTs involving $659 \mathrm{HCC}$ patients to evaluate the efficacy of post-operative TACE [80]. They found that post-operative TACE significantly decreased the 1- and 3 -year mortality of HCC with multiple nodules of $>5 \mathrm{~cm}$ or vascular invasion.

Furthermore, 2 papers evaluated both preoperative and post-operative TACE in combination with hepatic resection for HCC. In 2003, Mathurin et al. published a meta-analysis to evaluate the adjunctive chemotherapy after curative resection for HCC [81]. In their meta-analysis, the modality of chemotherapy was not restricted. Both transarterial chemotherapy with and without embolization were included. Among them, 10 and 7 studies evaluated the roles of pre- and post-operative transarterial chemotherapy, respectively. They found that only post-operative transarterial chemotherapy, but not pre-operative transarterial chemotherapy, improved the survival and decreased the probability of no recurrence. In 2014, Cheng et al. performed a meta-analysis of 10 RCTs involving 909 patients to assess the beneficial and harmful effects of pre-operative and post-operative TACE for curative resection of HCC [82]. Among them, 4 and 6 trials assessed the outcomes of pre-operative and post-operative TACE, respectively. In line with the findings by Mathurin et al., they also found that pre-operative TACE did not improve DFS and OS for curative resection of $\mathrm{HCC}$, but post-operative TACE achieved significant improvement of DFS and OS in patients with tumor size $>5 \mathrm{~cm}$.

Most of previous meta-analyses suggested that the adjunctive use of pre-operative TACE was not effective, but post-operative TACE might be beneficial for the improvement of DFS and OS. By comparison, our study had several strengths. First, both pre-operative and post-operative TACE were evaluated. Second, both RCTs and non-RCTs were included. Certainly, the subgroup analysis was divided into RCTs and nonRCTs groups. In addition, non-RCTs could reflect the real-world conditions more accurately. Third, both OS and DFS were evaluated. Fourth, the search strategy was more extensive, and the number of included studies was larger. Fifth, the study quality was strictly evaluated according to the well-known scales or tools. Sixth, the subgroup analysis was performed to explore the efficacy of pre-operative and post-operative TACE. Seventh, the HR was calculated to show a trend over time, but not an odds ratio at some time point.

In agreement with the recommendations from current practice guidelines [5], the overall meta-analysis did not find any significant benefits of TACE before hepatic resection. Notably, if the tumor necrosis was incomplete or lacking, pre-operative TACE would 


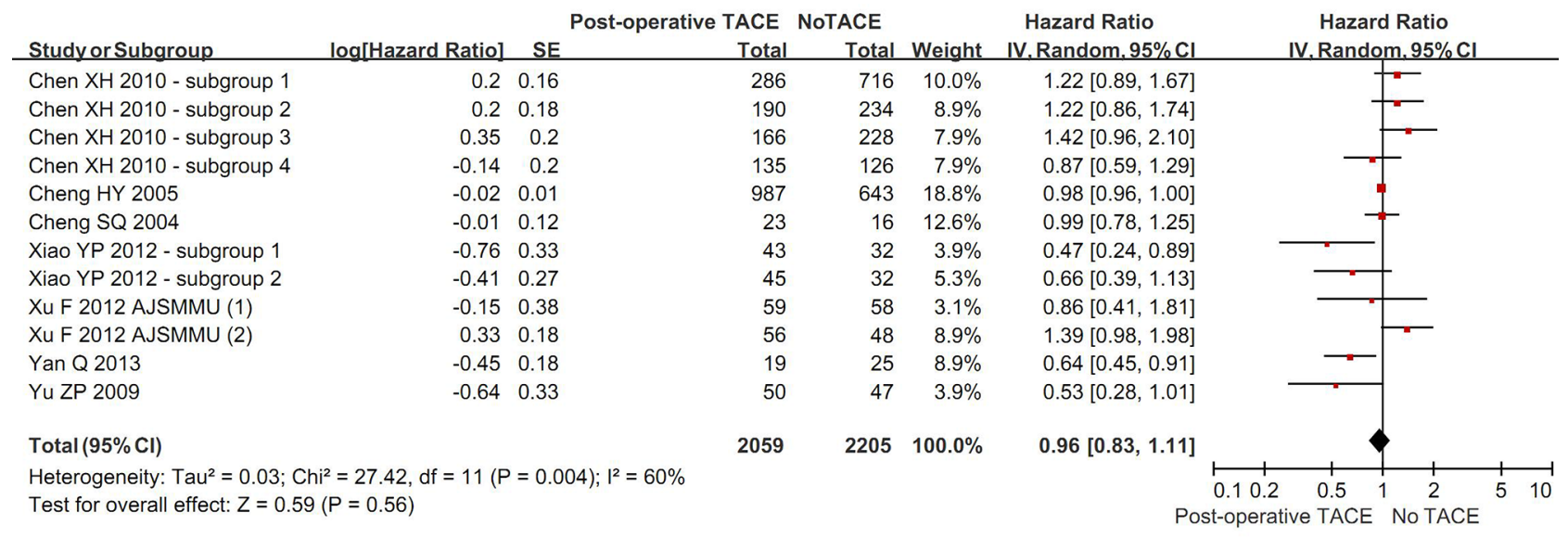

Figure 6: Forest plots comparing the rate of being free of recurrence between hepatic resection with and without postoperative TACE groups.

deteriorate the OS of HCC patients treated with hepatic resection. By comparison, if the tumor necrosis was complete, pre-operative TACE would improve the DFS of HCC patients treated with hepatic resection. Thus, whether or not the use of TACE was valuable before hepatic resection might be largely dependent upon the grade of tumor necrosis. Further studies should be helpful to identify the candidates who had a higher probability of complete tumor necrosis induced by pre-operative TACE.

We also found that the efficacy of pre-operative TACE was not influenced by the tumor size or study design. Additionally, in the setting of liver cirrhosis, pre-operative TACE might significantly improve the OS and DFS of HCC patients treated with hepatic resection. However, it should be noted that only a small number of studies were included in these subgroup analyses.

In contrast with the previous meta-analyses [8182], we did not find a statistically significantly better OS in post-operative TACE group than in no postoperative TACE group. However, a trend towards the improvement of OS by post-operative TACE should be clearly recognized. Besides, the DFS was significantly improved by post-operative TACE. As we looked at the subgroup results, the OS and DFS benefit of postoperative TACE was statistically significant in patients with more advanced HCC (i.e., vascular invasion or large HCC). On the contrary, the OS and DFS were statistically similar between the two groups in patients with less advanced HCC (i.e., no vascular invasion and small HCC). Indeed, both vascular invasion and large HCC are associated with a higher rate of tumor recurrence after hepatic resection. In such patients, the adjunctive use of post-operative TACE might be more worthwhile to further improve the patients' prognosis.

We also found that the subgroup results of post-operative TACE were different between RCTs and non-RCTs. In the subgroup meta-analysis of RCTs, the OS and DFS were significantly improved by post- operative TACE. More importantly, we did not observe any statistically significant heterogeneity among these included RCTs ( $\mathrm{I}^{2}=0 \%$ in both subgroup analyses). By contrast, in the subgroup meta-analyses of non-RCTs, the OS and DFS were not significantly different between hepatic resection with and without post-operative TACE groups. The heterogeneity among studies was significant ( $\mathrm{I}^{2}=69 \%$ in the OS analysis; $\mathrm{I}^{2}=73 \%$ in the DFS analysis). This discrepancy may be attributed to the potential bias in the patient and treatment selection among the non-RCTs, in which post-operative TACE might be more frequently employed for the patients with a higher probability of tumor recurrence after hepatic resection. Thus, the outcomes became similar between the two groups.

Our study had several limitations. First, we observed statistically significant heterogeneities in the overall meta-analyses. This might be primarily because the patients' characteristics and treatment selection were different among studies. We attempted to conduct the subgroup analyses to explore the sources of heterogeneity. For example, as for pre-operative TACE, the heterogeneity became not significant in the OS subgroup analysis of large HCC, liver cirrhosis, and RCTs, but remained significant in the OS subgroup analysis of small HCC and non-RCTs. In addition, we employed only random-effect models to produce conservative results. Certainly, given such a statistically significant heterogeneity among studies, we had to acknowledge that our conclusions should be cautiously interpreted. Second, a majority of included studies were non-RCTs. To overcome this limitation, we attempted to perform the subgroup meta-analyses according to the study design. Third, the quality of included studies was unsatisfactory. Most of RCTs had the potential risk of bias in the allocation concealment and blinding methods. Notably, TACE was an interventional radiological procedure, rather than a drug. Thus, it might be impractical to blind the treatment assignment. Fourth, the information regarding TACE techniques, 
anticancer drugs, and embolization drugs was lacking or heterogeneous among studies. Thus, we could not compare the difference among them. Fifth, most of included papers regarding post-operative TACE were from oriental countries. Some of them were published in Chinese language, so the original data were hardly understood by Western readers. Certainly, their primary items were selectively shown in our paper.

In conclusion, based on the present systematic review and meta-analysis, pre-operative TACE should not be considered as an adjunctive treatment option of HCC. But it should be never neglected that preoperative TACE can lead to complete necrosis of HCC in selected cases, thereby improving the DFS after hepatic resection. Thus, we should further identify the candidates who are potentially eligible for pre-operative TACE. On the other hand, post-operative TACE should be recommended, especially in patients with more advanced HCC treated with hepatic resection. However, due to the relatively poor quality of included studies, well-designed RCTs should be warranted to confirm these findings.

\section{MATERIALS AND METHODS}

This work was registered with PROSPERO (registration number: CRD42015019207).

\section{Search strategy}

The PubMed, EMBASE, and Cochrane Library databases were searched. As previously described [83], search items were as follows: ("hepatectomy" OR "liver resection" OR "hepatic resection" OR "liver surgery" OR "hepatic surgery") AND ("TACE" OR "transarterial chemoembolization") AND ("HCC" OR "hepatocellular carcinoma" OR "hepatic carcinoma"). The last search was performed on December 18, 2014. Relevant literatures were also manually searched.

\section{Study selection}

The inclusion criteria should be as follows.

Participants: patients should be diagnosed with HCC irrespectively of tumor stage.

Interventions: in the experimental group, patients should undergo hepatic resection in combination with pre-operative or post-operative TACE; and in the control group, patients should undergo hepatic resection alone. If hepatic resection was performed in combination with systemic chemotherapy or transarterial infusion of chemotherapy rather than TACE, they would not be considered as experimental groups. Additionally, it should be noted that post-operative TACE should be prophylactic but not therapeutic. In other words, if TACE was employed for the treatment of recurrent
HCC or residual tumor after hepatic resection, it would not be considered as experimental groups. The interval between TACE and hepatic resection was not arbitrarily restricted.

Comparisons: the outcomes should be compared between patients undergoing hepatic resection in combination with and without TACE. There were two different conditions according to the timing of TACE and hepatic resection. They should include hepatic resection in combination with pre-operative TACE versus hepatic resection alone and hepatic resection in combination with post-operative TACE versus hepatic resection alone.

Outcomes: the outcomes observed should include OS, recurrence-free survival or DFS, time-to-recurrence, and/or recurrence rate. Notably, both recurrencefree survival and DFS were considered as the same outcome "DFS".

The exclusion criteria should be as follows.

1. Duplicate papers among databases or redundant publications [84].

2. Narrative or systematic reviews or study protocols.

3. Comments.

4. Experimental studies.

5. Case reports.

6. Hepatic metastases.

7. Mixed malignancies.

8. Non-comparative studies.

9. No comparison between hepatic resection versus TACE.

10. Comparison between hepatic resection versus TACE for HCC.

11. No separate data in two groups.

12. No detailed data regarding the survival rate in two groups.

Type of study design was not restricted. Either randomized or non-randomized studies were eligible in the systematic review. Publication status and language were not restricted. If two or more papers by the same study team had the overlapping data, only one paper with more adequate data and/or a longer enrollment period would be included.

\section{Data extraction}

The following data were extracted: the first author, publication year, publication form, region, enrollment period, study design, study population, follow-up time, inclusion and exclusion criteria, number of HCC cases, timing of TACE, interval between TACE and hepatic resection, OS rate, DFS rate, rate free of recurrence, and their corresponding KaplanMeier curve analyses with log-rank test. If the propensity score matching analysis was performed, we just collected the survival data after the propensity score matching analyses. If both survival rates and Kaplan-Meier curves were presented, only the survival rates would be collected. If only KaplanMeier curves were presented, we extracted the cumulative 
1-, 3-, and 5-year survival rates by using the Distance Tool in the Measurements menu of Foxit PDF Reader software (Foxit Cooperation, California, USA). This software was freely downloaded.

\section{Study quality}

The quality of cohort and case-control studies was evaluated according to the Newcastle-Ottawa scales for the cohort and case-control studies, respectively [85]. Newcastle-Ottawa scale was composed of 3 major sections with 8 questions, such as Selection section with 4 questions, Comparability section with 1 question, and Exposure section with 3 questions. A study can be given a maximum of 1 point for each question within the Selection and Exposure sections, and a maximum of 2 points for the sole question within the Comparability section. follows:

The 8 relevant questions for cohort studies were as

1. Selection section: representativeness of hepatic resection in combination with TACE group.

2. Selection section: selection of hepatic resection alone group.

3. Selection section: ascertainment of hepatic resection in combination with TACE group.

4. Selection section: demonstration that outcome of interest was not present at start of study.

5. Comparability section: comparability of cohorts on the basis of the design or analysis.

6. Outcome section: assessment of outcome.

7. Outcome section: was follow-up long enough for outcomes to occur.

8. Outcome section: adequacy of follow up of cohorts.

The 8 relevant questions for case-control studies were as follows:

1. Selection section: definition of hepatic resection in combination with TACE group.

2. Selection section: representativeness of hepatic resection in combination with TACE group.

3. Selection section: selection of hepatic resection alone group.

4. Selection section: definition of hepatic resection alone group.

5. Comparability section: comparability of cohorts on the basis of the design or analysis.

6. Outcome section: ascertainment of outcome.

7. Outcome section: same method of ascertainment for cases and controls.

8. Outcome section: non-response rate.

The quality of RCTs was evaluated according to the Cochrane Collaboration's tool for assessing the risk of bias. This tool was composed of 6 sections, such as random sequence generation (selection bias), allocation concealment (selection bias), blinding of participants and personnel (performance bias), blinding of outcome assessment (detection bias), incomplete outcome data addressed (attrition bias), and selective reporting (reporting bias). "High risk", "low risk", or "unclear risk" was given to every section.

\section{Data analysis}

Meta-analyses were performed by the statistical package Review Manager version 5.3.5 (Copenhagen, The Nordic Cochrane Center, The Cochrane Collaboration, 2014). Only random-effects models were employed. Because the OS, DFS, and rate free of recurrence were the time-dependent data, the HRs with $95 \%$ CIs were pooled by using the calculation sheets developed by Tierney et al [86]. Heterogeneity between studies was assessed by using the $\mathrm{I}^{2}$ statistic and the Chi-square test. $\mathrm{I}^{2}>50 \%$ or $P<0.10$ was considered to represent a significant heterogeneity. Funnel plots were performed to evaluate the publication bias. If all studies laid within $95 \% \mathrm{CI}$, there was no proof of publication bias. Otherwise, there was a proof of publication bias. As for the pre-operative TACE, the subgroup meta-analyses were performed according to the tumor necrosis after TACE (complete tumor necrosis versus incomplete or no tumor necrosis), tumor size (large HCC versus small HCC), liver cirrhosis (cirrhotic versus non-cirrhotic), and type of study design (RCT versus non-RCT). Generally, large HCC was arbitrarily defined as the largest diameter of $\mathrm{HCC}$ was $>5 \mathrm{~cm}$; by contrast, small HCC was defined as the largest diameter of $\mathrm{HCC}$ was $\leq 5 \mathrm{~cm}$. Additionally, the definitions of large and small HCC were extracted and followed according to every included paper. As for the post-operative TACE, the subgroup meta-analyses were performed according to the vascular invasion (vascular invasion versus no vascular invasion or extrahepatic spread), tumor size (large HCC versus small HCC), liver cirrhosis (cirrhotic versus non-cirrhotic), and type of study design (RCT versus non-RCT). Subgroup difference was assessed by using the $\mathrm{I}^{2}$ statistic and the Chi-square test. $\mathrm{I}^{2}>50 \%$ or $P<0.10$ was considered as having a significant subgroup difference.

\section{ACKNOWLEDGMENTS AND FUNDING}

None.

\section{CONFLICTS OF INTEREST}

The authors report no declarations of interest.

\section{Authors' contributions}

XQ: designed the study, performed the literature search and selection, data extraction, quality assessment, 
and statistical analysis, and drafted the manuscript; LL and DW: performed the literature selection, data extraction, and quality assessment; CS: performed the literature search; HL and XG: gave critical comments and revised the manuscript. All authors have made an intellectual contribution to the manuscript and approved the submission.

\section{REFERENCES}

1. El-Serag HB. Hepatocellular carcinoma. N Engl J Med. 2011; 365:1118-27.

2. Forner A, Llovet JM, Bruix J. Hepatocellular carcinoma. Lancet. 2012; 379:1245-55.

3. Franco D, Capussotti L, Smadja C, Bouzari H, Meakins J, Kemeny $\mathrm{F}$, et al. Resection of hepatocellular carcinomas. Results in 72 European patients with cirrhosis. Gastroenterology. 1990; 98:733-8.

4. Balsells J, Charco R, Lazaro JL, Murio E, Vargas V, Allende E, et al. Resection of hepatocellular carcinoma in patients with cirrhosis. Br J Surg. 1996; 83:758-61.

5. Bruix J, Sherman M. Management of hepatocellular carcinoma: an update. Hepatology. 2011; 53:1020-2.

6. Qi X, Tang Y, An D, Bai M, Shi X, Wang J, et al. Radiofrequency ablation versus hepatic resection for small hepatocellular carcinoma: a meta-analysis of randomized controlled trials. J Clin Gastroenterol. 2014; 48:450-7.

7. Feng Q, Chi Y, Liu Y, Zhang L, Liu Q. Efficacy and safety of percutaneous radiofrequency ablation versus surgical resection for small hepatocellular carcinoma: a meta-analysis of 23 studies. J Cancer Res Clin Oncol. 2015; 141:1-9.

8. Roayaie S, Jibara G, Tabrizian P, Park JW, Yang J, Yan L, et al. The Role of hepatic resection in the treatment of hepatocellular cancer. Hepatology. 2015.

9. Farinati F, Vanin V, Giacomin A, Pozzan C, Cillo U, Vitale A, et al. BCLC stage B hepatocellular carcinoma and transcatheter arterial chemoembolization: a 20-year survey by the Italian Liver Cancer group. Liver Int. 2015; 35:223-31.

10. Vitale A, Burra P, Frigo AC, Trevisani F, Farinati F, Spolverato G, et al. Survival benefit of liver resection for patients with hepatocellular carcinoma across different Barcelona Clinic Liver Cancer stages: A multicentre study. J Hepatol. 2015; 62:617-24.

11. Poon RT, Fan ST, Lo CM, Ng IO, Liu CL, Lam CM, et al. Improving survival results after resection of hepatocellular carcinoma: a prospective study of 377 patients over 10 years. Ann Surg. 2001; 234:63-70.

12. Adachi E, Maeda T, Matsumata T, Shirabe K, Kinukawa N, Sugimachi K, et al. Risk factors for intrahepatic recurrence in human small hepatocellular carcinoma. Gastroenterology. 1995; 108:768-75.

13. Okada S, Shimada K, Yamamoto J, Takayama T, Kosuge T, Yamasaki S, et al. Predictive factors for postoperative recurrence of hepatocellular carcinoma. Gastroenterology. 1994; 106:1618-24.

14. Llovet JM, Bruix J. Systematic review of randomized trials for unresectable hepatocellular carcinoma: Chemoembolization improves survival. Hepatology. 2003; 37:429-42.

15. Jung DH, Lee SG, Hwang S, Kim K, Ahn CS, Ha TY, Song GW, Park GC, Youn YI, Kim WJ. Neoadjuvant transcatheter arterial embolization and portal vein embolization before major hepatectomy for single hepatocellular carcinoma no larger than $10 \mathrm{~cm}$ located in right liver. HPB. Asan Medical Center, Ulsan University South Korea: 2014; 299-300.

16. Hwang S, Lee SG, Lee YJ, Kim KH, Park KM, Ahn CS, Moon DB. Surgical outcome of HCC greater than $10 \mathrm{~cm}$ : Singlecenter experience of 471 cases. HPB. Asan Medical Center, Ulsan University South Korea: 2014; 187.

17. Kim BW, Wang HJ, Kim MW. Does transcatheter arterial chemoembolization before curative resection for hepatocellular carcinoma improve outcomes? HPB. Ajou University, School of Medicine South Korea: 2010; 311.

18. Lu W, Li YH, He XF, Zhao JB, Chen Y, Mei QL. Necrosis and apoptosis in hepatocellular carcinoma following low-dose versus high-dose preoperative chemoembolization. Cardiovascular and interventional radiology. 2008; p.1133-40.

19. Luo YQ, Wang Y, Chen H, Wu MC. Influence of preoperative transcatheter arterial chemoembolization on liver resection in patients with resectable hepatocellular carcinoma. Hepatobiliary Pancreat Dis Int. 2002; 1:523-6.

20. Ding YK, Lv WJ, Zhou CZ, Lu D, Tang WJ. The influence of postoperative TACE on the survival time and prognosis in hepatocellular carcinoma patients after liver resection. Journal of Interventional Radiology (China). 2014; 23:299-302.

21. Lin Z, Ren Z, Xia J. Appraisal of postoperative transcatheter arterial chemoembolization (TACE) for prevention and treatment of hepatocellular carcinoma recurrence. Zhonghua Zhong Liu Za Zhi. 2000; 22:315-7.

22. Adachi $E$, Matsumata $T$, Nishizaki $T$, Hashimoto $H$, Tsuneyoshi M, Sugimachi K. Effects of preoperative transcatheter hepatic arterial chemoembolization for hepatocellular carcinoma. The relationship between postoperative course and tumor necrosis. Cancer. 1993; 72:3593-8.

23. Cheng $\mathrm{HY}, \mathrm{Xu} \mathrm{W}, \mathrm{Xu} \mathrm{AM}$, Chen $\mathrm{D}$, Yang YF, Jia YC. Evaluation of transcatheter arterial chemoembolization in the prevention of postoperative recurrence in 1630 patients with hepatocellular carcinoma. Zhonghua Zhong Liu Za Zhi. 2005; 27:626-8.

24. Cheng SQ, Wu MC, Chen H, Shen F, Yang JH, Cong WM, et al. Transcatheter hepatic arterial chemoembolization and thymosin alpha1 in postoperative treatment of hepatocellular carcinoma. Zhonghua zhong liu za zhi [Chinese journal of oncology]. 2004; 26:305-7. 
25. Cheng SQ, Wu MC, Chen H, Shen F, Yang JH, Cong WM, et al. Hepatocellular carcinoma with tumor thrombi in the portal vein. A comparison of therapeutic effects by different treatments. Zhonghua zhong liu za zhi [Chinese journal of oncology]. 2005; 27:183-5.

26. Chen XH, Zhang BH, Yin X, Qiu SJ, Fan J, Ren ZG, et al. Effect of postoperative adjuvant transarterial chemoembolization upon early recurrence after radical resection of hepatocellular carcinoma. Zhonghua Yi Xue Za Zhi. 2010; 90:826-9.

27. Chen XP, Hu DY, Zhang ZW, Zhang BX, Chen YF, Zhang WG, et al. Role of mesohepatectomy with or without transcatheter arterial chemoembolization for large centrally located hepatocellular carcinoma. Dig Surg. 2007; 24:208-13.

28. Choi GH, Kim DH, Kang CM, Kim KS, Choi JS, Lee WJ, et al. Is preoperative transarterial chemoembolization needed for a resectable hepatocellular carcinoma? World J Surg. 2007; 31:2370-7.

29. Di Carlo V, Ferrari G, Castoldi R, De Nardi P, Bergamo C, Taccagni G, et al. Pre-operative chemoembolization at hepatocellular carcinoma in cirrhotic patients. HepatoGastroenterology. 1998; 45:1950-4.

30. Gerunda GE, Neri D, Merenda R, Barbazza F, Zangrandi F, Meduri F, et al. Role of transarterial chemoembolization before liver resection for hepatocarcinoma. Liver Transpl. 2000; 6:619-26.

31. Hanazaki K, Kajikawa S, Shimozawa N, Mihara M, Shimada K, Hiraguri M, et al. Survival and recurrence after hepatic resection of 386 consecutive patients with hepatocellular carcinoma. J Am Coll Surg. 2000; 191:381-8.

32. Harada T, Matsuo K, Inoue T, Tamesue S, Nakamura H. Is preoperative hepatic arterial chemoembolization safe and effective for hepatocellular carcinoma? Ann Surg. 1996; 224:4-9.

33. Izumi R, Shimizu K, Iyobe T, Ii T, Yagi M, Matsui O, et al. Postoperative adjuvant hepatic arterial infusion of Lipiodol containing anticancer drugs in patients with hepatocellular carcinoma. Hepatology. 1994; 20:295-301.

34. Jianyong L, Jinjing Z, Wentao W, Lunan Y, Qiao Z, Bo L, et al. Preoperative transcatheter arterial chemoembolization for resectable hepatocellular carcinoma: a single center analysis. Ann Hepatol. 2014; 13:394-402.

35. Kaibori M, Tanigawa N, Matsui Y, Saito T, Uchida Y, Ishizaki $\mathrm{M}$, et al. Influence of transcatheter arterial chemoembolization on the prognosis after hepatectomy for hepatocellular carcinoma in patients with severe liver dysfunction. Anticancer Research. 2006; 26:3685-92.

36. Kaibori M, Tanigawa N, Kariya S, Ikeda H, Nakahashi Y, Hirohara J, et al. A prospective randomized controlled trial of preoperative whole-liver chemolipiodolization for hepatocellular carcinoma. Digestive diseases and sciences. 2012; p.1404-12.

37. Kang JY, Choi MS, Kim SJ, Kil JS, Lee JH, Koh KC, et al. Long-term outcome of preoperative transarterial chemoembolization and hepatic resection in patients with hepatocellular carcinoma. Korean J Hepatol. 2010; 16:383-8.

38. Kim IS, Lim YS, Lee HC, Suh DJ, Lee YJ, Lee SG. Preoperative transarterial chemoembolization for resectable hepatocellular carcinoma adversely affects post-operative patient outcome. Aliment Pharmacol Ther. 2008; 27:338-45.

39. Kishi Y, Saiura A, Yamamoto J, Koga R, Seki M, Morimura R, et al. Preoperative transarterial chemoembolization for hepatocellular carcinoma. Hepatogastroenterology. 2012; 59:2295-9.

40. Lee KT, Lu YW, Wang SN, Chen HY, Chuang SC, Chang WT, et al. The effect of preoperative transarterial chemoembolization of resectable hepatocellular carcinoma on clinical and economic outcomes. Journal of Surgical Oncology. 2009; 99:343-50.

41. Li F, Guo Z, Zhang Y, Wang H, Zhang X, Si T, et al. Postoperative adjuvant arterial chemoembolization improves the survival of hepatitis B virus-related hepatocellular carcinoma: a retrospective control study. Ir J Med Sci. 2014.

42. Li JQ, Zhang YQ, Zhang WZ, Yuan YF, Li GH. Randomized study of chemoembolization as an adjuvant therapy for primary liver carcinoma after hepatectomy. J Cancer Res Clin Oncol. 1995; 121:364-6.

43. Li KW, Wen TF, Li X, Yan LN, Li B, Zeng Y, et al. The effect of postoperative TACE on prognosis of HCC with microscopic venous invasion. Hepato-Gastroenterology. 2012; 59:1944-6.

44. Li Q, Wang J, Sun Y, Cui YL, Juzi JT, Qian BY, et al. Postoperative transhepatic arterial chemoembolization and portal vein chemotherapy for patients with hepatocellular carcinoma: a randomized study with 131 cases. Digestive surgery. 2006; p.235-40.

45. Li Q, Wang J, Sun Y, Cui YL, Juzi JT, Li HX, et al. Efficacy of postoperative transarterial chemoembolization and portal vein chemotherapy for patients with hepatocellular carcinoma complicated by portal vein tumor thrombosis-a randomized study. World J Surg. 2006; 30:2004-11. discussion 12-3.

46. Liu YJ, Zhang XM, Zhang JX, Cheng YS, Yang RJ, Li MQ. Transarterial chemoembolization as an adjuvant therapy in patients with hepatocellular carcinoma treated with hepatectomy. Chinese Journal of Radiology. 2010; 44:847-51.

47. Lu CD, Peng SY, Jiang XC, Chiba Y, Tanigawa N. Preoperative transcatheter arterial chemoembolization and prognosis of patients with hepatocellular carcinomas: retrospective analysis of 120 cases. World J Surg. 1999; 23:293-300.

48. Majno PE, Adam R, Bismuth H, Castaing D, Ariche A, Krissat J, et al. Influence of preoperative transarterial lipiodol chemoembolization on resection and transplantation for hepatocellular carcinoma in patients with cirrhosis. Ann Surg. 1997; 226:688-701. discussion -3.

49. Nagasue N, Galizia G, Kohno H, Chang YC, Hayashi T, Yamanoi A, et al. Adverse effects of preoperative hepatic 
artery chemoembolization for resectable hepatocellular carcinoma: a retrospective comparison of 138 liver resections. Surgery. 1989; 106:81-6.

50. Nishikawa H, Arimoto A, Wakasa T, Kita R, Kimura T, Osaki Y. Effect of transcatheter arterial chemoembolization prior to surgical resection for hepatocellular carcinoma. Int J Oncol. 2013; 42:151-60.

51. Ochiai T, Sonoyama T, Hironaka T, Yamagishi $H$. Hepatectomy with chemoembolization for treatment of hepatocellular carcinoma. Hepatogastroenterology. 2003; 50:750-5.

52. Park JH, Han JK, Chung JW, Han MC, Kim ST. Postoperative recurrence of hepatocellular carcinoma: results of transcatheter arterial chemoembolization. Cardiovasc Intervent Radiol. 1993; 16:21-4.

53. Paye F, Jagot P, Vilgrain V, Farges O, Borie D, Belghiti J. Preoperative chemoembolization of hepatocellular carcinoma: a comparative study. Arch Surg. 1998; 133:767-72.

54. Peng BG, He Q, Li JP, Zhou F. Adjuvant transcatheter arterial chemoembolization improves efficacy of hepatectomy for patients with hepatocellular carcinoma and portal vein tumor thrombus. Am J Surg. 2009; 198:313-8.

55. Ren ZG, Lin ZY, Xia JL, Ye SL, Ma ZC, Ye QH, et al. Postoperative adjuvant arterial chemoembolization improves survival of hepatocellular carcinoma patients with risk factors for residual tumor: a retrospective control study. World J Gastroenterol. 2004; 10:2791-4.

56. Sasaki A, Iwashita Y, Shibata K, Ohta M, Kitano S, Mori M. Preoperative transcatheter arterial chemoembolization reduces long-term survival rate after hepatic resection for resectable hepatocellular carcinoma. Eur J Surg Oncol. 2006; 32:773-9.

57. Shi HY, Wang SN, Wang SC, Chuang SC, Chen CM, Lee KT. Preoperative transarterial chemoembolization and resection for hepatocellular carcinoma: a nationwide Taiwan database analysis of long-term outcome predictors. J Surg Oncol. 2014; 109:487-93.

58. Sugo H, Futagawa S, Beppu T, Fukasawa M, Kojima K. Role of preoperative transcatheter arterial chemoembolization for resectable hepatocellular carcinoma: relation between postoperative course and the pattern of tumor recurrence. World J Surg. 2003; 27:1295-9.

59. Tang QH, Zhou JP, Fu SY, Zhou WP. Effect of preoperative transcatheter arterial chemoembolization for treatment of resectable large hepatocellular carcinoma: A clinical randomized controlled trial. Academic Journal of Second Military Medical University. 2009; 30:1379-84.

60. Uchida M, Kohno H, Kubota H, Hayashi T, Yamanoi A, Kimoto $\mathrm{T}$, et al. Role of preoperative transcatheter arterial oily chemoembolization for resectable hepatocellular carcinoma. World J Surg. 1996; 20:326-31.

61. Wang QX, Yan JJ, Zhou FG, Shen J, Yan YQ. Exploration of indication of prophylactic transcatheter arterial chemoembolization on postoperative recurrence of hepatocellular carcinoma. Zhonghua wai ke za zhi [Chinese journal of surgery]. 2009; 47:748-51.

62. Wang TH, Ren ZG, Ye QH, Xia JL, Ye SL, Fan J, et al. Effect of preoperative adjuvant transcatheter hepatic arterial chemoembolization on prognosis of resectable huge hepatocellular carcinoma. Chinese Journal of Cancer Prevention and Treatment. 2010; 17:1210-3.

63. Wu CC, Ho YZ, Ho WL, Wu TC, Liu TJ, P'Eng FK Preoperative transcatheter arterial for resectable large hepatocellular carcinoma: a reappraisal. Br J Surg. 1995; $82: 122-6$.

64. Xi T, Lai EC, Min AR, Shi LH, Wu D, Xue F, et al. Adjuvant transarterial chemoembolization after curative resection of hepatocellular carcinoma: a non-randomized comparative study. Hepatogastroenterology. 2012; 59:1198-203.

65. Xiao EH, Hu GD, Li JQ, Huang JF. Transcatheter arterial chemoembolization in the treatment of hepatocellular carcinoma. Zhonghua Zhong Liu Za Zhi. 2005; 27:478-82.

66. Xiao YP, Liu TS, Ruan TY, Pan GD, Xiao Y. Value of transcatheter arterial chemoembolization with gemcitabine plus oxaliplatin in preventing postoperative recurrence of hepatocellular carcinoma in high-risk patients. World Chinese Journal of Digestology. 2012; 20:238-42.

67. Xu F, Huang YQ, Li YS, Wu L, Yang JM. Is postoperative adjuvant transchatheter arterial chemoembolization necessary for small hepatocellular carcinoma patients: A randomized controlled trial. Academic Journal of Second Military Medical University. 2012; 33:274-9.

68. Xu F, Huang YQ, Wu L, Yang JM. Postoperative adjuvant transcatheter arterial chemoembolization for hepatocellular carcinoma: A prospective study. Academic Journal of Second Military Medical University. 2012; 33:390-4.

69. Yamasaki S, Hasegawa H, Kinoshita H, Furukawa M, Imaoka $\mathrm{S}$, Takasaki $\mathrm{K}$, et al. A prospective randomized trial of the preventive effect of pre-operative transcatheter arterial embolization against recurrence of hepatocellular carcinoma. Jpn J Cancer Res. 1996; 87:206-11.

70. Yan Q, Ni J, Zhang GL, Yao X, Yuan WB, Zhou L, et al. Efficacy of postoperative antiviral combined transcatheter arterial chemoembolization therapy in prevention of hepatitis B-related hepatocellular carcinoma recurrence. Chin Med J (Engl). 2013; 126:855-9.

71. Yanaga K. Preoperative treatment for marginally-resectable advanced HCC: Con. HPB. 16 Jikei University, School of MedicineJapan 2014; 54.

72. Yang PS, Hsieh CB, Chen TW, Chan DC, Yu JC. Comparison the result among liver transplantation and liver resection with or without pre-operative TACE for hepatocellular carcinoma patients within milan criteria. Liver Transplantation. Division of General Surgery, Department of Surgery, Mackay Memorial Hospital Taipei, Taiwan: 2010; S192-S3.

73. Yu ZP, Xu ZK, Zhou WZ, Hu WH, Yu C, Zeng QQ. Yuan fa xing gan ai gen zhi shu hou fu zhu gan dong mai shuan 
shai hua liao yu fang gan nei fu fa de liao xiao (Article in Chinese). Shi Yong Yi Xue Za Zhi. 2009; 25:1819-21.

74. Zhang Z, Liu Q, He J, Yang J, Yang G, Wu M. The effect of preoperative transcatheter hepatic arterial chemoembolization on disease-free survival after hepatectomy for hepatocellular carcinoma. Cancer. 2000; 89:2606-12.

75. Zhong C, Guo RP, Li JQ, Shi M, Wei W, Chen MS, et al. A randomized controlled trial of hepatectomy with adjuvant transcatheter arterial chemoembolization versus hepatectomy alone for Stage III A hepatocellular carcinoma. J Cancer Res Clin Oncol. 2009; 135:1437-45.

76. Zhou WP, Lai EC, Li AJ, Fu SY, Zhou JP, Pan ZY, et al. A prospective, randomized, controlled trial of preoperative transarterial chemoembolization for resectable large hepatocellular carcinoma. Ann Surg. 2009; 249:195-202.

77. Wang X, Li J, Peng Y, Dai Y, Xu W. Influence of preoperative transarterial chemoembolization on the prognosis for patients with resectable hepatocellular carcinoma: a metaanalysis of randomized trials. Hepatogastroenterology. 2011; 58:869-74.

78. Yu T, Xu X, Chen B. TACE combined with liver resection versus liver resection alone in the treatment of resectable HCC: A meta-analysis. Chinese-German Journal of Clinical Oncology. 2013; 12:P532-P6.

79. Zhou Y, Zhang X, Wu L, Ye F, Su X, Shi L, et al. Meta-analysis: preoperative transcatheter arterial chemoembolization does not improve prognosis of patients with resectable hepatocellular carcinoma. BMC Gastroenterol. 2013; 13:51.
80. Zhong JH, Li LQ. Postoperative adjuvant transarterial chemoembolization for participants with hepatocellular carcinoma: A meta-analysis. Hepatol Res. 2010; 40:943-53.

81. Mathurin P, Raynard B, Dharancy S, Kirzin S, Fallik D, Pruvot FR, et al. Meta-analysis: evaluation of adjuvant therapy after curative liver resection for hepatocellular carcinoma. Aliment Pharmacol Ther. 2003; 17:1247-61.

82. Cheng X, Sun P, Hu QG, Song ZF, Xiong J, Zheng QC. Transarterial (chemo)embolization for curative resection of hepatocellular carcinoma: a systematic review and metaanalyses. J Cancer Res Clin Oncol. 2014; 140:1159-70.

83. Qi X, Wang D, Su C, Li H, Guo X. Hepatic resection versus transarterial chemoembolization for the initial treatment of hepatocellular carcinoma: A systematic review and metaanalysis. 2015; 6:18715-33.

84. Qi X, Yang M, Ren W, Jia J, Wang J, Han G, et al. Find duplicates among the PubMed, EMBASE, and Cochrane Library Databases in systematic review. PLoS One. 2013; 8:e71838.

85. Wells GA, Shea B, O'Connell D, Peterson J, Welch V, Losos M, et al. The Newcastle-Ottawa Scale (NOS) for assessing the quality of nonrandomised studies in metaanalyses. http://wwwohrica/programs/clinical_epidemiology/ oxfordasp.

86. Tierney JF, Stewart LA, Ghersi D, Burdett S, Sydes MR. Practical methods for incorporating summary time-to-event data into meta-analysis. Trials. 2007; 8:16. 